\title{
UNIVERSIDADE DE SÃO PAULO \\ ESCOLA DE ENFERMAGEM DE RIBEIRÃO PRETO \\ CENTRO COLABORADOR DA ORGANIZAÇÃO MUNDIAL \\ DA SAÚDE-OMS
}

QUALIDADE DE VIDA DO PACIENTE COM ESTOMA INTESTINAL SECUNDÁRIA AO CÂNCER CÓLON-RETAL

SIMONE YURIKO KAMEO

Ribeirão Preto

2006 
QUALIDADE DE VIDA DO PACIENTE COM ESTOMA INTESTINAL SECUNDÁRIA AO CÂNCER CÓLON-RETAL

SIMONE YURIKO KAMEO

Linha de Pesquisa: Processo de cuidar do adulto com doenças agudas e crônicodegenerativas.

Orientadora: Namie Okino Sawada

Ribeirão Preto

2006 
Autora: Simone Yuriko Kameo

Qualidade de vida do paciente com estoma intestinal secundária ao câncer cólonretal

Natureza da pesquisa: Dissertação

Grau: Mestre

Instituição: Universidade de São Paulo - Escola de Enfermagem de Ribeirão Preto. Programa de Pós-graduação Enfermagem Fundamental

Área de concentração: Enfermagem Oncológica

Data da aprovação: I

Banca examinadora

\section{Dra Namie Okino Sawada}

Livre docência em Enfermagem Médico- Cirúrgico

Universidade de São Paulo- Brasil

Márcia Maria Fontão Zago

Livre docência em Enfermagem Médico-Cirúrgico

Universidade de São Paulo - Brasil

Manoel Antônio dos Santos

Doutorado em Psicologia Clínica

Universidade de São Paulo - Brasil 


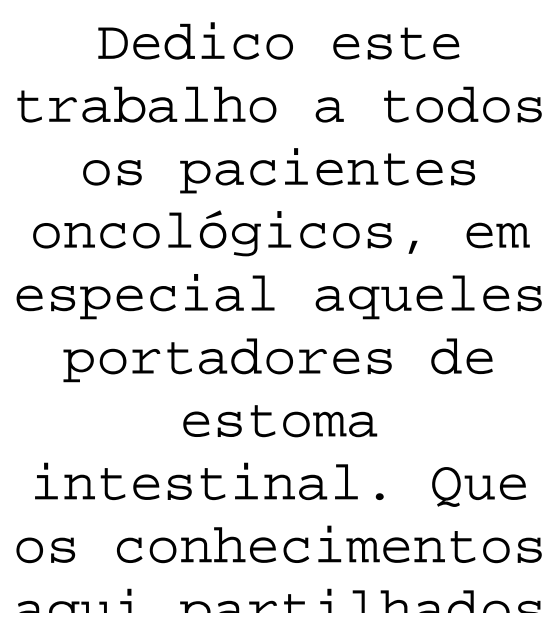


Agradeço a Deus por ter me dado a vida, minha família, meus amigos e coragem para buscar o que necessito. A Nossa Senhora de Aparecida pela proteção, por ter ouvido minhas preces e me coberto com seu manto.

À minha mãe querida por ser minha amiga antes de tudo, por estar sempre ao meu lado, mesmo estando longe e por me amar do seu jeito. Agradeço pelo cuidado, apoio, incentivo e orações .

Ao meu pai por estar sempre presente, mesmo estando distante, deixando de lado sua vida e me ajudando a enfrentar tantas pedras no meio da caminhada, por acreditar sempre em mim, incentivando-me a ser sempre uma pessoa melhor.

Ao meu irmãozinho querido, Sérgio, meu grande estímulo na luta deste sonho, por ser meu grande amigo, apesar de estar do outro lado do mundo, compartilhando os risos e as lágrimas, sempre disposto a me ajudar em todos os momentos.

Ao meu grande amor Filhotinho, por todo o carinho e confiança, sendo tão presente e tão importante na minha vida. Agradeço pelo amor, por desejar estar sempre ao meu lado, em todos os momentos.

À minha orientadora, Namie por ter aceitado me orientar, pela paciência, conhecimentos e incentivo nos momentos que fraquejei.

Às professoras Helena Megume Sonobe, Manoel A. dos Santos, Márcia M. F. Zago e Rosana Aparecida Spadoti Dantas pelo conhecimento transmitido e apoio durante minha vida 
acadêmica e pelas importantes contribuições neste trabalho.

Aos estatísticos Emílio e Adriano pelas brilhantes colocações e ajuda em todos os momentos.

Enfim, aos atores sociais, que me abriram a porta de suas casas e expuseram as suas aflições através de suas falas. Tal encontro encorajou-me a continuar este trabalho, apesar de todas as dificuldades.

À equipe de enfermagem do Centro de Oncologia do Hospital João Alves, pelo acolhimento e colaboração para a concretização deste estudo.

À todos os docentes do Curso de Enfermagem da EERP/USP, que através dos seus ensinamentos me elucidaram a bela arte de ser Enfermeiro.

À todos que, com amor e compreensão, me incentivaram nessa trajetória.

Muita obrigada!! 
Kameo, S. Y.Qualidade de vida do paciente com ostomia intestinal secundário ao câncer colo-retal.Dissertação de mestrado .2006.119p.Dissertação de mestrado. Escola de enfermagem de Ribeirão Preto, Universidade de São Paulo, Ribeirão Preto,2006.

\section{RESUMO}

O objetivo deste estudo foi investigar a qualidade de vida do paciente com estoma intestinal secundário ao câncer cólon-retal na cidade de Aracaju-Se. Trata-se de estudo descritivo-exploratório, na vertente quantitativa, utilizando-se um instrumento contendo três partes, dados sócio-demográficos e clínicos, itens referentes à Escala de Qualidade de Vida de Flanagan (EQVF), e EORTC-QLQ-C-30. A amostra constou de 18 pacientes atendidos no Centro de Oncologia Dr Oswaldo Leite, localizado na cidade de Aracaju - Sergipe no período de janeiro a dezembro de 2005. Os instrumentos mostraram propriedades psicométricas satisfatórias quanto à consistência interna e validade do construto. Quanto às características sóciodemográficas e clínicas, $50 \%$ eram do sexo feminino, e 50\% masculino. A média de idade foi de 51,3 anos. Quanto à localização do tumor, 38,9\% tumor de reto, seguida de cólon-retal 33,3\% e cólon 27,8\%. 83,3\% apresentavam metástase e 16,7\% não apresentavam. Em relação ao tipo de estoma, 72,2\% tinham colostomia definitiva e $27,8 \%$ colostomia provisória. $77,8 \%$ dos pacientes apresentaram menos de um ano de estoma e $22,2 \%$ mais de um ano de estoma. A análise de qualidade de vida da amostra mostra para EQVF média de 52,3 (DP=1,40) para EQVF Geral. Para EORTC QLQ-C30, a média estado geral de saúde foi de 35,64 (DP=12,39). Foram estatisticamente significativos os resultados obtidos nas escalas: relações com outras pessoas, atividades sociais e desenvolvimento pessoal e realização. Pacientes com menos de um ano de estoma, apresentam maior atividade social, 
desenvolvimento pessoal e realização do que aqueles com mais de um ano de estoma. Foram estatisticamente significativas as escalas: função física, dor, estado geral de saúde, dificuldades financeiras, dispnéia, fadiga, náusea e vômito, constipação e função emocional. A função física teve como variável estatisticamente significante o estado civil, com maior média entre pessoas casadas, assim como a escala dor, porém com maior média entre as pessoas viúvas. A função física entre as pessoas casadas foi maior. No sintoma dor, a presença desta, foi maior entre o grupo de pessoas viúvas e separadas. Na escala estado geral de saúde, foram estatisticamente significativos o sexo e complicações do estoma, com médias superiores entre aqueles do sexo masculino e com presença de complicações. $\mathrm{Na}$ escala dificuldades financeiras, a procedência e as complicações do estoma foram estatisticamente significantes. Com maiores médias entre aqueles da área rural e com presença de complicações do estoma. No sintoma dispnéia, a variável estatisticamente significante foi a presença ou não de metástase, com maior média entre aqueles com metástases. Já os sintomas fadiga, náusea e vômitos e constipação, apresentou como única variável estatisticamente significante o tempo de estoma. Na escala função emocional, a variável complicações do estoma foi estatisticamente significante, havendo maior média entre aqueles com presença de complicações do estoma. A escala relações com outras pessoas foi influenciada pelas variáveis: sexo, tempo de estoma e estado de origem, conforme cálculo de Regressão Linear Múltipla. As escalas função emocional, dispnéia, dificuldade financeira e estado geral de saúde tiveram influência das variáveis sexo, estado civil, estado de procedência, metástase, tempo de estoma e complicações.

Unitermos: Qualidade de vida, Câncer cólon-retal e Estoma intestinal. 
Kameo, S. Y Quality of life in patients with secondary intestinal ostomy after colorectal câncer. Dissertação de mestrado .2006.119p.Dissertação de mestrado. Escola de enfermagem de Ribeirão Preto, Universidade de São Paulo, Ribeirão Preto,2006.

\section{ABSTRACT}

The objective of this study was to investigate the quality of life of the patient with secondary intestinal estoma to the cancer colo-retal in the city of Aracaju-Se. This is an description-exploratory study, in the quantitative source, using an instrument contends three parts, given partner-demographic and clinical, itens referring to Scale of Quality of Life of Flanagan (EQVF), and EORTC QLQ-C30. The sample consisted of 18 patients taken care of in the Center of Oncologia Dr Oswaldo Leite located in the city of Aracaju - Sergipe in the period of January to December of 2005 . The instruments had shown to satisfactory psicometrics properties such as the internal consistency and validity of construct. About the partner-demographic and clinical characteristics, $50 \%$ were of the feminine sex, and $50 \%$ masculine. The age average was 51,3 years. About the localization of tumor, $38,9 \%$ tumor of rectum, followed $33,3 \%$ colo-rectum and colon $27,8 \%$. Metastase were presented by $83,3 \%$ and $16.7 \%$ didn't present. In relation to the type of stoma, $72,2 \%$ had definitive colostomia and $27,8 \%$ provisory colostomia. $77,8 \%$ of the patients had presented less than 1 year of stoma and 22,2\% more than 1 year of stoma. The analysis of quality of life of the sample shows for average EQVF of $52,3(\mathrm{DP}=1,40)$ for general EQVF. For EORTC QLQ-C30, the been average general of health was of 35,64 $(\mathrm{DP}=12,39)$. The scales had been statisticaly significant: social relations with other people, activities and personal development and accomplishment. Patients with less 
than one year of stoma, present greater social activity, personal development and accomplishment of that those with more than one year of stoma. The scales had been statistically significant: physical function, pain, general state of health, financial difficulties, dispneia, fatigue, nausea and vomit, constipation and emotional function. The physical function had as changeable statistically significant the civil state, with average greater between married people, as well as the scale pain, however with average greater between the people widowers. The physical function between the married people was bigger. In the symptom pain, the presence of this, it was bigger enters the group of people separate widowers and. In the scale general of health, the sex and complications of stoma had been statisticaly significant, with superior averages between those of the masculine sex and with presence of complications. In the scale financial difficulties, the origin and the complications of stoma they had been statisticaly significant. With average greaters between those of the agricultural area and with presence of complications of stoma. In the dispneia symptom, the statisticaly significant variable was the presence or not of metastase, with average greater it enters those with metastases. Already the symptoms fatigue, nausea and vomits and constipation, the stoma time presented as only statisticaly significant variable. In the scale emotional function, the variable complications of stoma was statisticaly significant, having bigger average between those with presence of complications of stoma. The scale Relations with other people was influenced by the variable: sex, time of stoma and state of origin, as calculation of Multiple Linear Regression. The scales emotional function, dispneia, financial difficulty and general state of health had had influence of the variable sex, civil state, state of origin, metastase, time of stoma and complications.

Key words: Quality of life, Cancer colo-rectal and Intestinal stoma. 
Kameo, S. Y.Calidad de vida del paciente con ostomía intestinal secundaria tras cancer colo-rectal. Dissertação de mestrado .2006.119p.Dissertação de mestrado. Escola de enfermagem de Ribeirão Preto, Universidade de São Paulo, Ribeirão Preto,2006.

\section{RESUMEN}

El objetivo de este trabajo fue investigar la calidad de vida del paciente con ostomía intestinal secundario al cáncer colorectal en la ciudad de Aracaju-SE. Se trata de un estudio descriptivo exploratorio en su variante cuantitativa, fue utilizado un instrumento con tres escalas, datos socio-demográficos y clínicos, referentes a la Escala de Calidad de Vida de Flanagan (EQVF) y EORTC QLQ - 30. La muestra fue formada por 18 pacientes atendidos en el Centro de Oncología Dr. Oswaldo Leite localizado en la ciudad de Aracaju - Sergipe, en el período de enero a diciembre de 2005. Los instrumentos mostraron propiedades psicometricas satisfactorias en lo referido a la consistencia interna y validad del construto. De las características sociodemográficas y clínicas, $50 \%$ eran del sexo femenino y $50 \%$ del masculino. La edad promedio era de 51,3 años. En cuanto a la localización del tumor, 38,9\% estaba localizado en el recto, seguido del colorectal con $33,3 \%$ y colon con $27,8 \% ; 83,3 \%$ de los pacientes presentaron metástasis contra $16,7 \%$ que no la presentaron. En relación con el tipo de ostomía, $72,2 \%$ tenían colostomía definitiva y $27,8 \%$ temporaria. $77,8 \%$ de los pacientes presentaron ostomía en un intervalo de tiempo inferior a un año y $22,2 \%$ en un intervalo superior a un año. El análisis de Calidad de Vida de la muestra, revela para EQVF un valor promedio de 52,3 (DP=1,40) para un EQVF general. Para EORTC QLQ-C30, el promedio del estado general de salud fue de 35,64 (DP=12,39). Fueron estadísticamente significativas las escalas: relaciones con otras personas, actividades sociales, desarrollo personal y realización. Pacientes con menos de un año de ostomía, presentaron una mayor actividad social, desarrollo 
personal y realización que aquellos con más de un año de incidencia. Fueron estadísticamente significativas las escalas: función física, dolor, estado general de salud, dificultades financieras, disnea, fatiga, nausea y vómito, constipación y función emocional. La función física tuvo como variable estadísticamente significativa el estado civil, con mayor incidencia entre las personas casadas, así como la escala dolor, pero con mayor incidencia entre las personas viudas. La función física entre las personas casadas fue mayor. El síntoma dolor, tuvo mayor presencia en el grupo de personas viudas y separadas. En la escala estado general de salud, fueron estadísticamente significativos el sexo y complicaciones del estoma, con valores medios superiores entre los del sexo masculino. En la escala dificultades financieras, la procedencia y las complicaciones del estoma fueron estadísticamente significativos, con mayores incidencias entre pacientes del área rural y con presencia de complicaciones del estoma. En el síntoma disnea, la variable estadísticamente significativa fue la presencia o no de metástasis, con mayor incidencia entre aquellos con metástasis. Ya los síntomas fatiga, nausea y vómitos y constipación, presentaron como única variable estadísticamente significativa el tiempo de ostomía. En la escala función emocional, la variable complicaciones del estoma fue estadísticamente significativa, teniendo una mayor incidencia entre aquellos con presencia de complicaciones del estoma. La escala relaciones con otras personas fue influenciada por las variables: sexo, tiempo de ostomía e estado de origen, conforme el cálculo de regresión lineal múltiple. Las escalas función emocional, disnea, dificultad financiera y estado general de salud, tuvieron influencia de las variables sexo, estado civil, estado de precedencia, metástasis tiempo de ostomía y complicaciones.

Palabras clave: Calidad de vida, Cáncer colorectal y Ostomía intestinal. 


\section{SUMÁRIO}

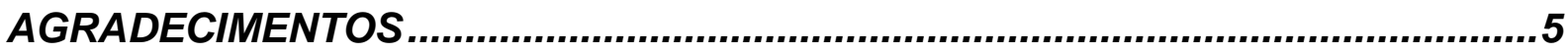

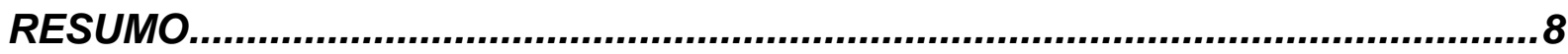

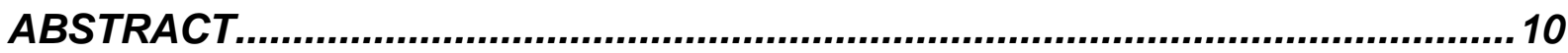

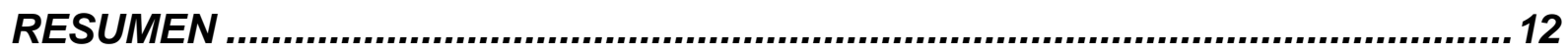

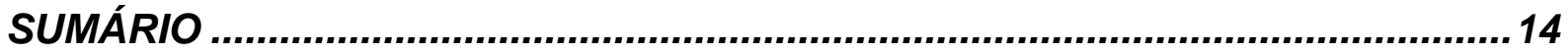

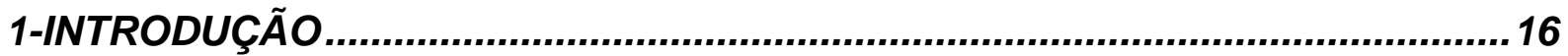

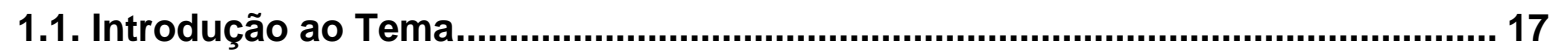

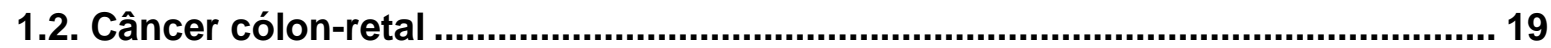

1.2.1. Epidemiologia e fatores de risco .................................................... 19

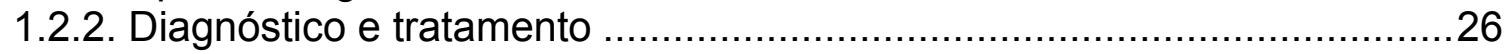

1.3. Qualidade de vida de indivíduos com estoma intestinal ...................................49

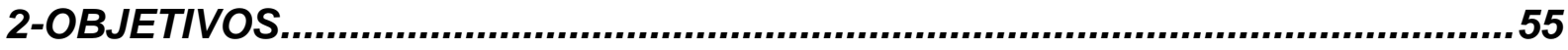

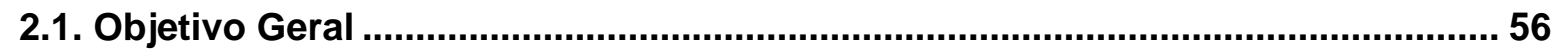

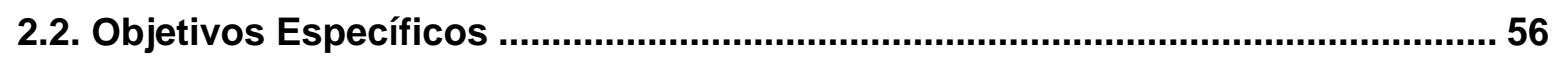

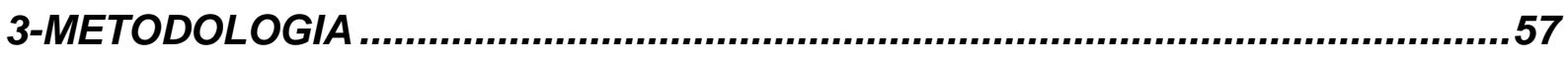

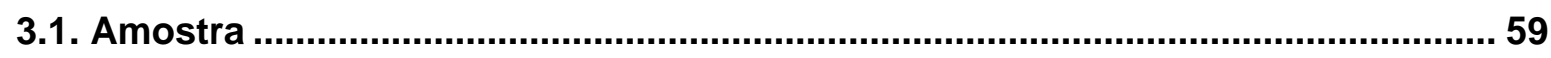

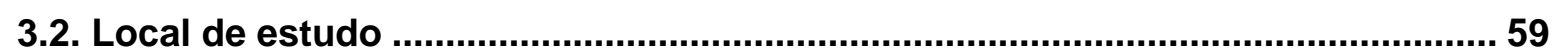

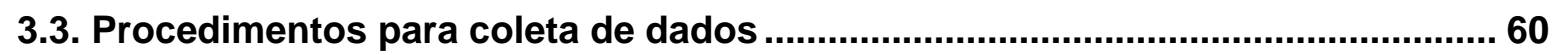

3.4. Descrição dos Instrumentos para avaliação da Qualidade de vida...................... 61

3.4.1 Escala de Qualidade de Vida de Flanagan .........................................61

3.4.2 European Organization for Research and Treatment of Câncer Quality of

Life Questionnaire "Core" 30-Items (EORTC-QLQ-C30) versão 3.0 em

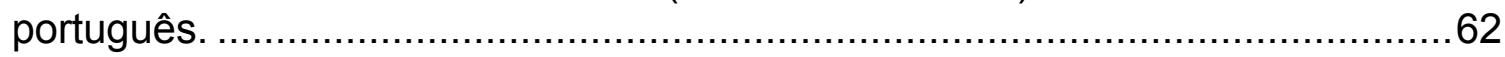

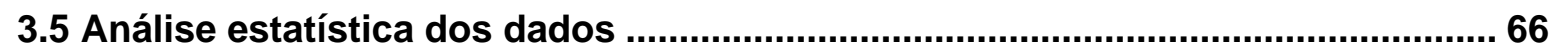

3.5.1 Métodos para validação dos instrumentos para Avaliação da Qualidade de

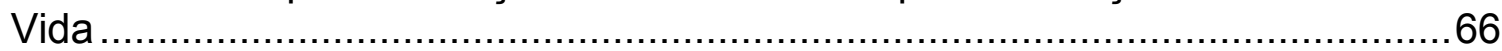

3.5.2 Verificação da associação entre as escalas dos Instrumentos para

Avaliação da Qualidade de Vida e as variáveis sócio demográficas e clínicas. .66

3.5.3 Validação dos instrumentos para avaliação da Qualidade de Vida...........67

4-RESULTADOS E DISCUSSÃO.................................................................... 72

4.1 Características Sócio-Demográficas, Clínicas e Terapêuticas ............................ 73

4.2 Resultados dos Instrumentos de Avaliação da Qualidade de Vida...................... 81

4.3 Relação entre as variáveis sócio-demográficas e clínicas e a qualidade de vida.

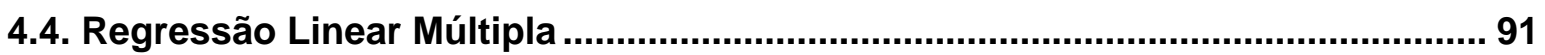

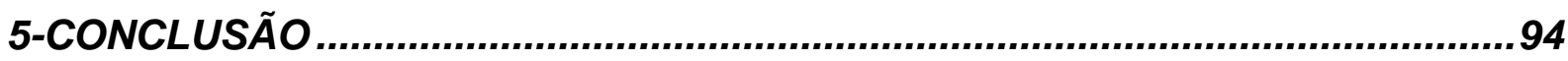

6-CONSIDERAÇÕES FINAIS...................................................................... 99 
7-REFERÊNCIAS BIBLIOGRÁFICAS.

102

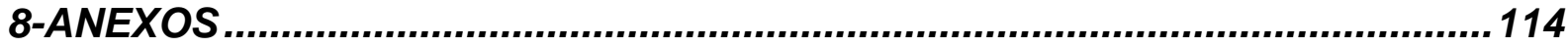

8.1 Anexo I: Termo de Consentimento Livre e Esclarecido..................................... 115

8.2 Anexo II: Coleta de dados sócio-clínico-demográficos dos estomizados ......... 116

8.3 Anexo III: Instrumento para coleta de dados sobre Qualidade de Vida -EORTC

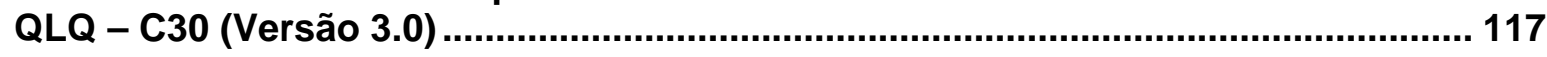

8.4 Anexo IV: Escala de qualidade de vida de Flanagan (1982) ............................. 119 


\subsection{Introdução ao Tema}

O convívio muito próximo a pessoas portadoras de câncer, teve início na Residência em Enfermagem Oncológica, no Instituto Nacional de Câncer, na cidade do Rio de Janeiro, no período de 2002 a 2004. A partir daí, pude perceber suas angústias, incertezas, medos e dúvidas, já que em torno do câncer geram inúmeras fantasias e metáforas que o associam com a morte. O simples fato de utilizar-se a palavra câncer para designar um conjunto de patologias tumorais já indica a necessidade da integração entre os vértices psicológicos e médicos. A pronúncia da palavra câncer suscita fantasias de dor, morte e sofrimento, substituem por "aquela doença", como se evocasse uma entidade demoníaca de grande poder de destruição. Por esses motivos desafiadores do câncer, estava convicta de que meu caminhar acadêmico não se encerrava naquele momento. Ao buscar a Escola de Enfermagem de Ribeirão Preto/USP, procurei dar continuidade aos estudos que focalizam o tema oncologia.

Sempre estive inquieta com a facticidade desta clientela, aquelas com câncer e estoma, assim, logo me inseri no atendimento a estes clientes, junto ao Serviço de Estomaterapia do INCa, pois para mim a estoma significava algo muito traumatizante e agressivo.

Assim, a minha motivação foi conhecer o universo singular e próprio do portador de neoplasia e estoma, buscando as necessidades destas pessoas pela avaliação da qualidade de vida para subsidiar uma assistência qualificada

Estar com uma parte do intestino para fora do corpo, precisamente localizado no abdômen, preso na pele, onde ocorre a eliminação de fezes, tem sido relatado 
pelos pacientes como uma situação bastante significativa. A partir deste ponto, comecei a refletir e pude perceber que todos nós temos um modo particular de olhar o mundo.

Os estudos acerca da qualidade de vida nos levam a compreender a individualidade do cliente, especificamente o cliente oncológico, e ajudá-los a tomar a melhor decisão relacionada às opções acerca de seu tratamento.

Após a elaboração do projeto, fui coletar dados na cidade de Aracaju-Se, devido à mudança familiar. Esta mudança tornou-se um grande desafio devido às diversas dificuldades encontradas, entre elas a difícil missão de se encontrar dados estatísticos de câncer cólon-retal, já que inexiste um banco de dados, sendo necessário recorrer aos médicos proctologistas e oncologistas, onde me guiaram e me mostraram caminhos para encontrá-los. Além disso, deparei com serviços desestruturados, onde os clientes são submetidos a cirurgias e não são acompanhados sistematicamente, profissionais despreparados, falta e até desperdício de materiais para curativos, serviços desqualificados, entre outros itens.

De qualquer forma, não podemos esquecer que o câncer continua sendo uma enfermidade qualitativa e quantitativamente muito importante em nossa sociedade. Sua incidência e os índices de mortalidade são cada vez mais elevados.

Como temática da dissertação do Curso de Mestrado em Enfermagem, esta pesquisa elegeu investigar a qualidade de vida da pessoa portadora de câncer e estoma intestinal, que passa a ser meu objeto de estudo. 


\subsection{Câncer cólon-retal}

\subsubsection{Epidemiologia e fatores de risco}

Com o aumento da expectativa de vida da população brasileira, as neoplasias vêm ganhando cada vez maior importância no perfil de mortalidade do país, ocupando o segundo lugar como causa de óbito e configurando-se como um problema de saúde pública. Neste contexto, o câncer do cólon e reto, encontra-se entre os dez primeiros tipos de câncer mais incidentes no Brasil, tanto no sexo masculino como no feminino [1].

No entanto, muitas dessas mortes poderiam ser evitadas. Ao observar-se a história natural do câncer cólon-retal, verifica-se que esta propicia condições ideais à sua prevenção e detecção precoce, uma vez que na maioria das vezes evoluem a partir de lesões benignas, os pólipos adenomatosos, após um período de 10 a 15 anos [1].

O câncer cólon-retal é a terceira causa mais comum de morte por câncer, no Brasil. Possui maior incidência na faixa etária entre 50 e 70 anos, mas as possibilidades de desenvolvimento já aumentam a partir dos 40 anos [2]. É também a terceira causa mais comum no mundo, em ambos os sexos, sendo a segunda causa em países desenvolvidos [3].

Segundo as Estimativas de Incidência e Mortalidade por Câncer no Brasil, publicadas pelo Instituto Nacional de Câncer (INCA) [4], o número de casos novos previstos para o ano 2006 é de 472.050 casos. Os tipos mais incidentes, à exceção de pele não melanoma, serão os de próstata e pulmão no sexo masculino e mama e colo do útero para o sexo feminino, acompanhando a mesma magnitude observada no mundo. São esperados 234.570 casos novos para o sexo masculino e 237.480 
para sexo feminino. Estima-se que no ano de 2006, o câncer de pele não melanoma (116 mil casos novos) será o mais incidente na população brasileira, seguido pelos tumores de mama feminina (49 mil), próstata (47 mil), pulmão (27 mil), cólon e reto (25 mil), estômago (23 mil) e colo do útero (19 mil).

O número de casos novos de câncer de cólon e reto estimados para o Brasil em 2006 é de 11.390 casos em homens e de 13.970 em mulheres. Estes valores correspondem a um risco estimado de 12 casos novos a cada 100 mil homens e 15 para cada 100 mil mulheres [4].

Sem considerar os tumores de pele não melanoma, o câncer de cólon e reto em homens é o quarto mais freqüente nas regiões Sul (22/100.000), Sudeste (17/100.000) e Centro-Oeste (10/100.000). Nas regiões Nordeste (4/100.000) e Norte (3/100.000), ocupa a quinta e a sexta posição, respectivamente. Para as mulheres é o segundo mais freqüente (21/100.000) na região Sudeste, o terceiro nas regiões Sul (22/100.000), Centro-Oeste (10/100.000) e Nordeste (5/100.000), enquanto na região Norte (4/ 100.000) é o quinto mais freqüente [4].

No mundo, os tumores malignos que acometem o cólon e o reto a cada ano somam cerca de 945 mil casos novos, sendo a quarta causa mais comum de câncer no mundo e a segunda em paises desenvolvidos. O prognóstico desse tipo de câncer pode ser considerado de moderado a bom. É o segundo tipo de câncer mais prevalente no mundo (depois do câncer de mama), com uma estimativa de 2,4 milhões de pessoas vivas diagnosticadas nos últimos cinco anos. A sobrevida média mundial estimada é de 44\% [4].

O alto consumo de frutas, vegetais frescos, cereais, baixo consumo de carnes vermelhas e de bebidas alcoólicas bem como a prática de atividade física, estão associados a um baixo risco de desenvolver câncer cólon-retal. Os resultados do 
inquérito domiciliar nas 16 localidades analisadas apontaram que o percentual de indivíduos que referem consumir frutas/legumes/verduras cinco vezes ou mais por semana variou entre $51 \%$ e $81 \%$. O percentual de indivíduos insuficientemente ativos variou entre $28 \%$ e $55 \%$. A prevalência de excesso de peso (IMC $\geq 25$ ) variou entre $33 \%$ e $46 \%$ [4].

O câncer cólon-retal é uma doença predominantemente de indivíduos idosos, sendo diagnosticada em $90 \%$ dos casos em pacientes acima de 50 anos [5].

A incidência do câncer cólon-retal em pacientes com idade inferior a 40 anos varia entre 2 e $6 \%$. Em pacientes jovens, ressalta-se a necessidade de pesquisar condições que possam estar associadas ao desenvolvimento do câncer cólon-retal, como as doenças genéticas (polipose adenomatosa familiar, síndrome do câncer cólon-retal familial, síndrome de Peutz-Jeghers) ou inflamatórios (retocolite ulcerativa idiopática (RCUI), doença de Crohn, colite actínica) e outras. Há contínuo debate quanto ao prognóstico desta doença em pacientes jovens, acreditando-se que esses indivíduos desenvolvam tumores localmente mais agressivos e com maior capacidade de metastatizar-se quando comparados a indivíduos mais idosos [6].

As alterações celulares que resultam da exposição da mucosa intestinal aos agentes cancerígenos inicialmente se manifestam por lesões inflamatórias inespecíficas. Se esta agressão é intensa e prolongada, levará ao desenvolvimento de displasias. Estas podem evoluir desde um grau leve até intenso e, finalmente, para o carcinoma in situ [3].

A grande maioria, senão todos os cânceres do intestino grosso, provêm de displasia epitelial acentuada, acrescida de alterações na diferenciação, crescimento e proliferação celular, que determinam a formação do adenoma (pólipo adenomatoso) e, subseqüentemente, do adenocarcinoma [3]. 
A lesão morfológica mais precoce no adenocarcinoma é uma cripta longa e dilatada, chamada cripta aberrante. A seqüência adenoma-câncer representa a contrapartida morfológica da carcinogênese por múltiplos passos dirigidas por alterações genéticas [3].

Transformações malignas do epitélio cólon-retal tipicamente ocorrem após um processo com várias etapas, caminhos e foco, que requer danos cumulativos em vários genes. A chave molecular do processo de desarranjo genético e/ou epigenético envolve o rompimento da fidelidade genômica, sinal transformador, divisão celular, apoptose, angiogênese, e limite comportamental, são essenciais para progressão da neoplasia [3].

O adenoma ou pólipo adenomatoso tem papel fundamental no desenvolvimento do câncer, sendo reconhecida como sua única lesão precursora [3].

A mais forte evidência indireta de que os pólipos adenomatosos originam câncer provém do estudo do "National Polyp Study" (NPS), conduzido nos Estados Unidos. Nesse estudo, 1418 pacientes foram submetidos a colonoscopia e tiveram todos os pólipos encontrados removidos. Após seguimento de seis anos, observouse uma redução de 76 e $90 \%$ na incidência de câncer do intestino em relação a três populações de referência. Quanto ao potencial maligno de pólipos adenomatosos, foi demonstrado no NPS que o risco de câncer aumenta para um adenoma com o seu tamanho e quando sua histologia é do tipo vilosa. A transformação maligna de um pólipo maior que $1 \mathrm{~cm}$ ocorreu em período médio de 5,5 anos e de pólipos menores, em cerca de 10 anos, demonstrando a designada seqüência adenomacâncer. Estes cânceres foram detectados por colonoscopia e não pela presença dos 
sintomas, o que demonstra, de acordo com este estudo, a longa evolução natural do câncer originado de um adenoma [7].

Discute-se se, em certo número de casos, o câncer do intestino pode se desenvolver sem passar pela seqüência adenoma-câncer. Nas doenças inflamatórias crônicas intestinais é provável que focos pequenos e planos de displasia epitelial possam desencadear a via histogenética, à semelhança do que ocorre para o câncer gástrico e do esôfago [7].

Estima-se que, em até $75 \%$ dos casos, o câncer de intestino possa ser classificado como esporádico, isto é, de caráter não familiar e resultante da ação cumulativa de agentes carcinógenos mais ou menos conhecidos sobre a mucosa intestinal. Entre os fatores relacionados ao seu desenvolvimento, encontram-se, principalmente, a idade (sendo a maioria dos casos diagnosticada após os 60 anos) e dietas pobres em frutas, verduras e legumes e ricas em gordura animal (o que pode ser responsável por 66 a $75 \%$ dos casos de câncer de cólon e reto). Além destes, indivíduos com história de parentes de primeiro grau com adenomas diagnosticados antes dos 60 anos de idade; história pessoal pregressa de adenomas ou câncer de mama, ovário ou endométrio; e portadores de colite ulcerativa crônica ou Doença de Crohn também apresentam risco aumentado de desenvolverem câncer do intestino. Cerca de $7 \%$ dos casos deste câncer estão associados a algumas condições hereditárias, como a polipose adenomatosa familiar (FAP, do inglês: "Familial adenomatous polyposis") e o câncer cólon-retal hereditário sem polipose (HNCCP, do inglês: "Hereditary non-polyposis colorectal cancer") [8].

O baixo nível de atividade física é um dos fatores mais reconhecidos como associado ao incremento no risco de desenvolvimento do câncer do intestino. Sua 
prática regular pode diminuir o risco de doença em até $50 \%$. O mecanismo responsável por este efeito parece estar relacionado à diminuição do tempo de trânsito intestinal, minimizando assim o contato de carcinógenos com as células do intestino. Algumas hipóteses sustentam ainda que a atividade física poderia alterar os níveis de prostaglandinas, melhorar o sistema imunológico e modificar o metabolismo dos ácidos biliares [8].

No tocante à dieta, a gordura animal tem sido apontada como uma das grandes vilãs. Existem evidências consideráveis de que um alto consumo de carnes vermelhas pode aumentar o risco de desenvolvimento do câncer de intestino. Vários mecanismos têm sido propostos para explicar essa associação, como a presença de ácidos graxos específicos contidos nesses alimentos e a de substâncias formadas durante o preparo das carnes em altas temperaturas como as aminas e os hidrocarbonetos aromáticos. Outros estudos, por sua vez, têm proposto que altas concentrações de ferro na carne vermelha poderiam ser a causa do maior risco para o desenvolvimento deste câncer, uma vez que este mineral está envolvido na síntese de radicais hidroxila, que podem causar danos às células do intestino [8].

Ao contrário, o alto consumo de frutas, verduras e fibras pode ter um papel protetor no desenvolvimento do câncer de intestino. Esse efeito pode ser justificado pelo alto teor de nutrientes e outras substâncias que podem inibir a formação de carcinógenos, agir como substratos para a produção de anticarcinógenos, reduzir a capacidade de proliferação de células e agir como antioxidantes [8].

O alto consumo desses alimentos pode ainda aumentar o bolo fecal e diminuir o tempo de trânsito intestinal e assim, minimizar o contato entre a mucosa e substâncias potencialmente carcinogênicas [8]. 
Uma série de micro-nutrientes parece estar associada a um efeito inibitório no desenvolvimento do câncer do intestino. Entre eles estão os fenóis, selênio, cálcio, vitaminas $A, C$ e $E$, e carotenos. Estas substâncias estão presentes em pequenas quantidades na água, cereais, frutas e vegetais. O cálcio é, talvez, o mais importante entre estes, uma vez que ajuda a diminuir o efeito das gorduras sobre as células intestinais. O consumo de alimentos e multivitamínicos que contêm folato pode contribuir para reduzir o risco de câncer de intestino, uma vez que a sua deficiência pode levar a anormalidades na síntese ou reparo do DNA [8].

Estudos mostram que o risco no desenvolvimento do câncer do intestino pode ser duas vezes maior em indivíduos que consomem bebidas alcoólicas em excesso. A exposição ao cigarro também pode aumentar o risco de desenvolver a doença, principalmente em caso de consumo por longos períodos de tempo [8].

A obesidade também parece aumentar o risco de desenvolvimento de pólipos adenomatosos e a progressão dos mesmos para malignidade. O acúmulo de grande quantidade de gordura abdominal parece estar associado mais fortemente a esse risco. É sugerido que a insulina e outros fatores relacionados ao crescimento sejam responsáveis pela influência positiva da obesidade no risco de câncer de intestino $[8]$.

Finalmente, é importante reconhecer que medidas dietéticas e comportamentais podem ter influência direta na diminuição do risco para o desenvolvimento do câncer cólon-retal. A adoção de hábitos saudáveis de vida, evitando o cigarro e o álcool, pode causar grande impacto na redução da incidência desta doença com benefícios pessoais, sociais e econômicos [8].

O câncer cólon-retal quando detectado em seu estágio inicial possui grandes chances de cura, diminuindo a taxa de mortalidade associada ao tumor. Pessoas 
com mais de 50 anos devem se submeter anualmente, ao exame de toque retal e ao exame de pesquisa de sangue oculto nas fezes [9].

A história natural do câncer do intestino propicia condições ideais à sua detecção precoce, uma vez que a maioria deles evolui a partir de lesões benignas, os pólipos adenomatosos, por um período de 10 a 15 anos, existindo, portanto, um período pré-clínico detectável bastante longo. Além disso, a detecção precoce do câncer do intestino apresenta a peculiaridade de possibilitar tanto a prevenção da ocorrência do câncer, ao possibilitar a identificação e retirada dos pólipos intestinais, quanto a detecção do câncer em estádios iniciais, que, adequadamente tratados, podem elevar a taxa de sobrevida em cinco anos a $90 \%$. Como resultado de avaliações epidemiológicas e de genética molecular, o rastreamento para câncer do intestino é realizado de acordo com a estimativa de risco para a neoplasia de cada população: baixo risco - indivíduos com idade superior a 50 anos e sem outros fatores de risco; risco moderado - pacientes com história familiar de câncer do intestino em um ou mais parentes de primeiro grau, história pessoal de pólipo maior do que um centímetro ou múltiplos pólipos de qualquer tamanho e os indivíduos com antecedente pessoal de câncer do intestino tratado com intenção curativa; alto risco em indivíduos com história familiar de FAP ou HNPCC, ou com diagnóstico de doença inflamatória intestinal na forma da pancolite ou colite esquerda [10].

\subsubsection{Diagnóstico e tratamento}

O protocolo de rastreamento para o câncer do intestino mais utilizado para população de risco baixo e moderado é a realização anual da pesquisa de sangue 
oculto nas fezes, seguida pela colonoscopia ou retossigmoidoscopia nos indivíduos com resultado positivo. As evidências científicas até o momento apontam para o início do rastreamento para o câncer do intestino com pesquisa de sangue oculto nas fezes a partir dos 50 anos de idade [10].

Para indivíduos com histórico de câncer de cólon e reto na família recomenda-se que, a partir dos 35 anos, seja realizado o exame de detecção de sangue oculto nas fezes e de uma endoscopia através do reto. Uma retossigmoidoscopia é recomendada a cada 3 anos, e, se for notada alguma alteração, deverá ser realizada a colonoscopia [9].

Em pacientes com mais de 30 anos e portadores da síndrome de Linch, é indicado colonoscopia e exame radiológico a cada 3 anos. Para indivíduos com histórico pessoal de câncer ou que apresentem pólipos recomenda-se uma endoscopia anualmente. Já nos casos de polipose familiar do tipo adenomatoso, a retirada do cólon através de cirurgia deve ser feita como medida preventiva. Pacientes com colite ulcerativa, devem realizar endoscopia anualmente [9].

O câncer cólon-retal em seu estágio inicial não produz sintomas, e quando há algum sinal, dificilmente este é associado ao diagnóstico do tumor. Alguns dos sintomas incluem: mudança do hábito intestinal como diarréia ou constipação, flatos, dor na região do abdome; náuseas; vômitos e emagrecimento. A hematêmese é muito comum, causando anemia e fraqueza [9].

Os sinais variam de acordo com o local do tumor. Quando o sangramento possui aspecto vermelho indica que o tumor situa-se na região mais distal do intestino. Quando está situado na região mais proximal, o sangramento apresenta uma coloração negra. Já o tumor no cólon direito tem como característica a presença de uma massa palpável [9]. 
O diagnóstico da doença é feito através de biópsia endoscópica com estudo histopatológico [9].

O prognóstico do câncer do intestino está claramente relacionado ao grau de infiltração tumoral na parede intestinal (categoria T), à presença ou ausência de envolvimento linfonodal (categoria $\mathrm{N}$ ), e à presença ou ausência de doença metastática (categoria M), ou seja, ao seu estadiamento clínico (pré-operatório) e anatomopatológico (pós-operatório) [11].

Para o câncer do intestino, o estadiamento é determinado pela avaliação da extensão de sua penetração na espessura da parede intestinal, pela presença ou ausência de tumor nos linfonodos (metástases linfáticas) que habitualmente fazem parte da estrutura anatômica do órgão, ou pela propagação do tumor para outros órgãos (metástases), das quais os mais freqüentes são fígado, pulmão e ossos [11].

O estadiamento definitivo envolve informações obtidas pelos resultados dos testes laboratoriais e radiológicos pré-operatórios, pelo patologista, através do exame histológico da peça cirúrgica retirada, e completado pela avaliação intraoperatória do cirurgião [11].

No pré-operatório a mensuração do antígeno carcino-embrionário (CEA) tem importância prognóstica e serve como parâmetro para acompanhamento pósoperatório. A investigação de eventuais metástases intra-abdominais e pélvicas deve ser feita por meio de exame ultrassonográfico (US) ou por tomografia computadorizada (TC). Já a investigação de metástases pulmonares deve ser efetuada por meio de exame radiológico simples de tórax. A Tomografia Computadorizada (TC) pode ser solicitada a critério clínico. Como a extensão da ressecção colônica está associada à presença de outras eventuais lesões, o exame colonoscópico faz também parte da pesquisa de eventuais lesões sincrônicas. A 
infiltração e extensão do tumor de reto devem ser avaliadas pelo toque retal e, quando possível, pela ultra-sonografia endorretal, principalmente para lesões pequenas, com possibilidade de tratamento local. No intra-operatório, a ampla inspeção da cavidade abdominal, por via aberta ou laparoscópica, com biópsias das eventuais lesões suspeitas é, sem dúvida, uma medida recomendável para direcionamento do tratamento adjuvante. A ultra-sonografia intra-operatória, quando disponível, está indicada para avaliar a presença de eventuais metástases hepáticas não diagnosticadas por outros métodos diagnósticos. A avaliação da agressividade tumoral e de sua capacidade de infiltração são feitas pelo exame anatomopatológico do material ressecado na cirurgia. Várias classificações foram propostas, sendo mais usada a originalmente descrita por Dukes e posteriormente modificada por AstlerColler. Atualmente a classificação proposta pela União Internacional de Combate ao Câncer foi recomendada para uso geral [11].

A remoção radical do câncer do reto, com propósitos curativos, por meio de procedimentos que combinam vias de acesso abdominal e perineal, foi introduzido no século passado, mas só se tornou bem conhecida, na Europa e nas Américas, a partir da publicação de Miles, em 1908 [12].

A protectomia, como argumentava Miles, removia o tumor e, junto com um segmento do cólon, os canais linfáticos regionais por onde a neoplasia se espalhava, não só nos sentidos proximal e distal, como laterais. Com essa cirurgia, ele enunciou os dois princípios que deveriam nortear o tratamento do câncer do reto. O primeiro baseava-se nos fatos obtidos com os estudos clínicos e anatomopatológicos dos espécimes cirúrgicos e o segundo, imposto pelo primeiro, orientava operação mais extensa quanto possível, não interessando a insignificância da lesão ou a precocidade de suas manifestações locais [12]. 
Essa conduta, apropriada para a época, sobreviveu, no entanto, em alguns centros, a despeito dos crescentes conhecimentos sobre o comportamento biológico do tumor, da importância prognóstica dada pelos métodos de estadiamento da lesão, relacionados à extensão de crescimento e ao grau de diferenciação celular e dos novos métodos de tratamento do câncer [12].

"O único tratamento possivelmente curativo é o cirúrgico. Apesar da ênfase de que se requer uma ressecção radical para ser curativa, todavia se seguem realizando ressecções limitadas... A sobrevivência pós-operatória está diretamente relacionada com o estádio da doença e o momento da ressecção cirúrgica".

Não há diferença entre câncer do reto e o câncer de outras localizações no intestino grosso. No entanto, o câncer de reto é o que desperta maior interesse, o que se deve, talvez, aos seguintes fatos: no reto, segmento de $16 \mathrm{~cm}$, localiza-se o maior número de adenocarcinomas do intestino grosso, numa variação que vai de 30 a $57 \%$; no segmento definido como reto baixo, que vai do anel anorretal e não ultrapassa a $2^{a}$ válvula, numa extensão não maior que $4 \mathrm{~cm}$, localiza-se de 25 a $30 \%$ dos tumores de reto; as manifestações clínicas denunciando a presença da lesão, em comparação a outros segmentos do intestino grosso, são mais antecipadas; a proximidade com o ânus torna a lesão mais acessível permitindo diagnóstico precoce e, portanto, em fases iniciais de crescimento do tumor [12].

Associados, ainda existem os relativos à sua anatomia. Fixo na pequena bacia, o reto mantém relação de vizinhança restrita, mesmo considerando seu segmento intraperitoneal, o que torna alvo fácil para a irradiação ionizante, cujos efeitos destinados às células neoplásicas podem ser favorecidos pela sua rica irrigação. Além disso, as dificuldades do acesso cirúrgico, conferida pela proteção do arcabouço ósseo da pequena bacia, pela bexiga, útero e estruturas nervosas 
controladoras de funções esfincterianas, têm sido minorada com as crescentes inovações táticas e de artifícios mecânicos que contribuíram para operações menos mutiladoras, que preservam a função, sem a perda dos propósitos oncológicos. Todavia, o domínio e aplicação desses conhecimentos, com as facilidades e vantagens inerentes, não tem se traduzido em resultados que expressem número de cura significante que o obtido em décadas passadas [12].

Dentre todos os elementos que reconhecidamente podem diminuir a recidiva local e, portanto, favorecer a cura do câncer de reto, maior destaque tem sido dado para a técnica cirúrgica. A importância da operação cirúrgica e da habilidade do cirurgião tem recebido ênfase. Há, ainda, procedimentos adjuvantes que, juntos com a operação, podem se não evitar as recidivas, pelo menos diminuí-las, substancialmente, aliviando cirurgiões e pacientes, da difícil tarefa de buscar, diante do insucesso, alternativas terapêuticas, enfrentando o conhecimento de que mais de $80 \%$ dos pacientes com recidiva local do câncer de reto, que foram anteriormente operados de forma curativa, morrerão em cinco anos [12].

A cirurgia consiste na retirada do tumor juntamente com parte do cólon ou reto e os linfonodos adjacentes. Os melhores resultados quanto às possibilidades de cura estão relacionados a cuidados técnicos de radicalidade, dentre os quais, extensão da ressecção quanto à remoção de linfonodos, ligaduras vasculares e margens cirúrgicas, ressecção completa em monobloco de órgãos ou estruturas vizinhas à lesão aderidas ao tumor [13].

Na maioria dos casos, é possível interligar novamente as porções sadias do cólon ou do reto. Em tumores da porção baixa do reto muitas vezes é necessária a realização de uma colostomia temporária ou permanente. Colostomia é um procedimento cirúrgico de exteriorização do cólon na parede abdominal (estoma) 
fornecendo assim um novo trajeto para a saída do material fecal. Após a realização de uma colostomia, o paciente utiliza uma bolsa especial para a coleta do material fecal. Alguns pacientes necessitam de uma colostomia temporária para permitir a cicatrização da anastomose após a realização da cirurgia. Cerca de $10 \%$ a $20 \%$ dos pacientes com câncer do reto necessitam de colostomia permanente [13].

Um tratamento cirúrgico é considerado curativo quando promove a remoção completa do tumor primário, órgãos e estruturas localmente comprometidas e de metástases identificadas, observados os preceitos técnicos oncológicos. É considerado paliativo quando tem por finalidade aliviar ou reduzir os sintomas em pacientes que não tenham condições de cura por ressecção (metástases irressecáveis à distância ou localmente disseminadas e invasão de estruturas vitais) [13].

Quimioterapia é o uso de drogas para destruir as células tumorais. A quimioterapia pode ser administrada para destruir qualquer célula cancerosa que possa ter permanecido no organismo após a cirurgia, para controlar o crescimento tumoral ou para aliviar os sintomas ocasionados pela doença. A quimioterapia é uma terapia sistêmica, o que significa que as drogas entram na circulação sangüínea e percorrem todo o organismo [13].

Terapia por radiação ou radioterapia $(\mathrm{RT})$, envolve o uso de raios-X de alta energia para destruir as células cancerosas. A radioterapia tem ação local, atingindo as células cancerosas localizadas apenas nas regiões que estão sendo tratadas [13].

Tanto a radioterapia como a quimioterapia podem ser utilizadas antes da cirurgia (terapia neoadjuvante) para redução da massa tumoral e assim facilitar a retirada cirúrgica do tumor, ou após a cirurgia (terapia adjuvante), para destruir 
células cancerosas que tenham permanecido na área tratada. A radioterapia também é utilizada para o alívio de sintomas. A radiação pode ser feita através de um aparelho externo (radiação externa) ou de um implante (um pequeno dispositivo composto por material radioativo) colocado diretamente no interior ou próximo ao tumor (radiação interna). Alguns pacientes são submetidos a ambos os tipos de terapia por radiação [13].

Pacientes em estádio III apresentam indicação de tratamento adjuvante com quimioterapia a base de 5 Fluorouracil (5-FU). Para pacientes em estádio II, o tratamento quimioterápico ainda é controverso, porém estudos indicam uma redução do risco de recidiva com uma vantagem de $2 \%$ em sobrevida livre em 5 anos para os pacientes tratados com terapia adjuvante com 5-FU quando comparados com grupos controle sem tratamento. O tratamento para pacientes com estádio IV é baseado em quimioterapia com objetivo paliativo. É considerado padrão o uso do 5FU combinado ou não com leucovorin, demonstrando- se aumentos variáveis de sobrevida [13].

O emprego da radioterapia ainda não é rotineiro para o câncer do cólon, devido à dificuldade em se estabelecer o volume de tratamento adequado. $O$ reto, por sua localização, na maior parte, abaixo da reflexão peritoneal tem no comportamento locorregional um importante indicador para radioterapia. Igualmente, as complexas redes de drenagem venosa e linfática propiciam disseminação sistêmica nos tumores transmurais justificando o emprego da quimioterapia. Cada vez mais a terapêutica multidisciplinar é utilizada, com tendência às operações mais conservadoras. O cuidado no acompanhamento após o tratamento do câncer cólonretal, é importante para assegurar que as alterações de saúde sejam relatadas e para o diagnóstico precoce e tratamento adequado de recidivas ou novos tumores. 
As avaliações poderão incluir, além do exame físico: colonoscopia, raio-X de tórax, testes laboratoriais e exames radiológicos como ultra-sonografia e tomografia. $\mathrm{O}$ suporte emocional é extremamente importante para promover melhor qualidade de vida dos doentes [13].

As primeiras operações abdominais, conhecidas através dos escritos de Aurelianus Caelius, ocorreram cerca do ano 300 AC e foram efetuadas por Praxágoras que interveio sobre o íleo, abrindo-o, evacuando-o e fechando-o novamente [14], [15].

Na Idade Média a medicina, especialmente a Anatomia Humana, teve sua evolução prejudicada pelos conceitos eclesiáticos do corpo sagrado, vigentes na época. Já, a partir da Renascença, essa área passou a ter um novo impulso pois os médicos novamente puderam proceder à autópsia. Porem, uma vez que a maioria desses procedimentos era efetuada em jovens saudáveis assassinados, os conhecimentos acerca das doenças não se desenvolveram significativamente [14], [15].

A radioterapia constitui-se num dos diversos métodos de terapêutica primária ou auxiliar, disponível para o tratamento coadjuvante do câncer do reto e tem sido considerada o segundo mais importante meio de prevenção da recidiva local [16].

No passado, os métodos radioterápicos convencionais eram, quase que exclusivamente, usados com propósitos paliativos, não só por causa da aparente resistência do tumor, como pelos efeitos colaterais representados pelas graves lesões de pele, ou queimaduras de órgãos internos, ao invés dos desejados resultados sobre a massa tumoral. O adenocarcinoma do reto era portanto, considerado rádio-resistente. 
Com o advento dos aparelhos de megavoltagem, capazes de gerar mais de 1 milhão de Volt, tais como as bombas de cobalto e os aceleradores lineares; dos conhecimentos sobre a radiobiologia e da influência da radiação sobre as células neoplásicas e o tecido normal; do melhor entendimento do comportamento clínico dos adenocarciomas; da efetividade e segurança dos métodos modernos de radiação, passíveis de aplicação sobre os tumores, fizeram desaparecer o conceito de rádio-resistência, destacando a radiação inclusive, como meio de tratamento primário de "casos" selecionados de câncer de reto [12].

Combinado com tratamento cirúrgico, o papel de destaque da radioterapia ficou bem estabelecido porque ela pode proporcionar ressecabilidade às lesões inicialmente consideradas inextirpáveis e diminuir a recidiva local de tumores ressecáveis. Para isso o método envolve, necessariamente, o conceito da "liberação de doses definidas capazes de erradicar células neoplásicas viáveis, provavelmente existentes na periferia dos tumores, com o mínimo dano para o tecido normal" [12].

No câncer cólon-retal a cirurgia é o seu tratamento primário, retirando a parte do intestino afetada e os linfonodos próximos a esta região. Muitos tumores do reto são tratados com cirurgias que preservam o esfíncter anal, através da utilização dos grampeadores, evitando assim as colostomias [9].

Após o tratamento cirúrgico, a radioterapia associada ou não à quimioterapia é utilizada para diminuir a possibilidade de recidiva do tumor. Quando a doença está disseminada, com metástases para o fígado, pulmão ou outros órgãos, as chances de cura diminuem [9].

Em estudo de Reis Neto et al [17], sobre radioterapia pré-operatória, constatam que a utilização desta como medida adjuvante ao tratamento cirúrgico do câncer retal, muito embora seja reconhecida como medida efetiva no controle do 
espaço-livre de câncer e da recidiva local, não tem sido utilizada como uma rotina na maior parte dos centros especializados nacionais.

Várias são as controvérsias responsáveis por tal fato: falta de consenso nacional sobre a dose total a ser utilizada e dose diária a ser aplicada, quantidade de dias nos quais a radioterapia será utilizada, determinação do intervalo de tempo entre o término da irradiação e a cirurgia, complicações cirúrgicas resultantes da radioterapia e sobre os efeitos da radioterapia no índice de sobrevida [17].

No entanto, torna-se evidente que toda esta controvérsia tem sido a escusa utilizada como jargão para a não utilização da radioterapia como medida adjuvante no tratamento do câncer de reto [17].

Inúmeros trabalhos anteriores, tanto prospectivos quanto retrospectivos, randomizados ou não, têm demonstrado que a associação da radioterapia préoperatória e cirurgia não só aumentam o intervalo-livre de câncer como diminuem a incidência de metástases locais e culminam por alterar positivamente a taxa de sobrevida pós-operatória [17].

Reis Neto et al [17] concluem que a radioterapia pré-operatória é realmente efetiva quanto ao efeito de redução do número de células indiferenciadas (carcinomatosas) e quanto à redução da infiltração tumoral na parede do reto. Ambos efeitos são os responsáveis pela baixa incidência de recidiva local e da mortalidade decorrente da mesma. O seguimento a longo prazo confirma a melhora na sobrevida, aumento estatisticamente significativo.

A radioterapia pré-operatória tem sido destacada como um método que deve ser usado de rotina em pacientes que são selecionados pelo alto risco de recidiva local, quando se objetiva efetivar o poder de cura da cirurgia [12]. 
Em qualquer órgão oco pode ser confeccionada uma estoma e, dependendo do segmento do corpo exteriorizado, recebem nomes diferenciados. Esta nova abertura recebe o nome de estoma ou estoma. A palavra "estoma" deriva do termo grego e significa "boca" ou "abertura" [12].

Estoma é o termo com que se designa a intervenção cirúrgica cujo objetivo é criar comunicação de uma víscera para o meio externo, através da parede abdominal. A estomia como técnica cirúrgica do aparelho digestivo, foi uma das intervenções mais antigas confeccionadas sobre o intestino, Praxágoras de Kós (350 a.C.) a realizava em casos de trauma abdominal [18].

"A estomaterapia, como especialidade na área de saúde, constituiu uma iniciativa de Dr. Rupert Turbull, da Cleveland Clinic, em Cleveland, Ohio... Surge então, a primeira especialista, Norma Gill, uma ileostomizada reabilitada e, portanto, com especial interesse na área..." "Em 1968, a criação da International Association of Enterostomal Therapy (IAET), permitiu o desenvolvimento de normas e padrões, não só para os cursos de Especialização, agora para enfermeiros, como também para os cuidados destinados a estomizados e portadores de fístulas, estes últimos aprovados pela American Nurse's Association..."

Ainda os mesmos autores citados por Foulkes, Jackson; Broadwell e Vukovich; Grubb [18], enfatizam que,

"O estomaterapêuta é o enfermeiro especialista com conhecimento, treinamento e habilidade para o cuidado de qualquer tipo de estomizado e de portadores de fístulas, feridas e incontinências fecal e urinária".

Pieper [19] reforça este pensar posicionando a enfermeira estomaterapêuta no cuidado a pacientes com estoma destacando que este profissional ajuda as pessoas adaptar-se nas trocas da imagem e função do corpo.

Este quadro demonstra, portanto, que a estomaterapia representa uma especialidade na área de saúde, onde para a enfermagem em particular reflete em âmbito nacional e internacional, buscas e conquistas para atender à crescente 
população de estomizados, demandas de qualidade de assistência, de pesquisa e de educação.

No Brasil, o papel do enfermeiro especialista toma forma, e torna-se realidade a partir do I Curso de Especialização em Estomaterapia, em 1990, pela Universidade São Paulo - SP, com carga horária de 365 horas, e conteúdo programático distribuídos em teoria e prática.

Colostomia e ileostomia são os estomas intestinais mais comuns, principalmente em pacientes oncológicos, e definidos, respectivamente, como abertura do cólon ou íleo na parede abdominal, objetivando o desvio do conteúdo intestinal para o meio externo [20].

As estomias podem ser classificadas de acordo com tempo de permanência, localização anatômica e tipo de construção do estoma [21].

Segundo o tempo de permanência podem ser: temporárias, aquelas em que se pode, posteriormente, restabelecer a continuidade do trato intestinal, uma vez que se tenha resolvido o problema que levou à confecção da estomia; definitivas ou permanentes, quando não se pode restabelecer o trânsito intestinal, já que o segmento distal do intestino foi extirpado [22].

Quanto à localização anatômica, segundo Brasil [22], as colostomias são divididas em ascendente ou direita, quando efetuadas no nível do cólon ascendente e localizada no quadrante superior direito do abdome. A transversa ou transversostomia, é efetuada no nível do cólon transverso e localizada geralmente, no ponto médio entre o rebordo costal e o umbigo. Já a descendente ou esquerda é confeccionada no cólon sigmóide e situada no quadrante inferior esquerdo do abdome. 
Segundo o tipo de construção ou técnica utilizada, são classificadas em terminal ou em alça. A ileostomia terminal é indicada nos casos de câncer avançado de reto, sendo a maioria definitiva. Ileostomia lateral ou em alça destina-se à proteção de anastomose íleo-anal ou íleo-retal, sendo este tipo temporária [21].

Colostomias em alça são as mais freqüentes, consistem em exteriorizar um segmento móvel do cólon, geralmente o cólon transverso, que se apóia sobre a pele através de um bastão. São indicados para proteção das anastomoses colo-anal ou cólon-retal, no tratamento da obstrução do cólon esquerdo, da perfuração do reto, no tratamento paliativo da neoplasia obstrutiva e no tratamento de processos infecciosos perineais graves [21].

As colostomias terminais, conforme o autor acima, são derivações definitivas criadas após uma grande cirurgia abdominal, podem ser confeccionadas em qualquer nível do cólon.

Considerações acerca da história dos estomas intestinais, deve-se segundo Kretschmer [23], à Tsilson Dinnick (Londres, 1934), com a publicação do artigo "As Origens e a evolução da Colostomia". Algumas muito importantes para compreensão do progresso das técnicas, outras bastantes curiosas mediante aos recursos existentes na época, esvaziando o seu conteúdo, fechando a seguir, porém com resultados desconhecidos.

Em 1710, Littré na França, foi o primeiro a recomendar a construção de uma colostomia, sua proposta foi recebida céticamente pela Académic Royal des Sciences francesa. Para o ano de 1750, Chelslden na Inglaterra, descreve um caso de ressecção de hérnia umbilical rota, com prolapso de intestino gangrenado com posterior ressecção do intestino prolapsado, e a conservação das extremidades abertas na hérnia. Já em 1850, Luke na Inglaterra foi o primeiro a realizar uma 
colostomia abdominal. Os anos se seguiram, até que em 1835, Konig e Rutzen projetaram um receptáculo de borracha com anel e cinto para ileostomias e colostomias [23].

Para os autores Santos e Souza Jr. [24], no que concerne a história, afirmam que:

"O surgimento dos estomas, em literatura, remonta ao séc. XVIII quando há referência da primeira colostomia realizada na esposa de um pescador, em 1750, resultante de uma intervenção num caso de hérnia encarcerada. Podemos imaginar a qualidade de vida apresentada por essa mulher ao tornar-se colostomizada, em uma época "carregada" de preconceitos e quando não havia o menor conhecimento sobre cuidados específicos ..."

Os principais marcos históricos referentes à construção de estomas, desde a mais remota antiguidade até os dias de hoje, confere às técnicas cirúrgicas um avanço considerável, mediante a diminuição da mortalidade e o risco de complicações pós-operatórias, bem como a busca do aprimoramento de materiais e equipamentos em estomaterapia. Entretanto, para cada pessoa portadora de estomia, esta condição não só ainda representa um impacto físico e psicológico, mas também uma súbita destruição de sua imagem corporal.

Deste modo, Bekkers [25], em seu estudo, aborda que o aperfeiçoamento das técnicas no cuidado de estomas, desde a década passada, não resultou no declínio dos problemas relacionados a adaptação psicossocial após a cirurgia para a confecção de estoma. Cita alguns fatores que contribuem para esta adaptação, tais como: a) características sócio-demográficas; b) aqueles relacionadas ao estoma, ou seja, inclui a técnica insuficiente para a confecção do mesmo, a pele peri-estoma mais sensível, e uma inabilidade do estomizado para o autocuidado; c) outras relacionadas à enfermidade onde, a adaptação psicossocial está associada ao diagnóstico médico e a diferenciação entre benignidade e malignidade representa 
particular importância, e d) aqueles relacionados a personalidade, tais como os fatores intrapessoal (traços e atitudes) e interpessoal (suporte social).

Tendo em vista a complexidade simbólica e vivencial do estomizado, o impacto do câncer e do estoma sobre o indivíduo e as alternativas para solucionar ou minimizar as dificuldades então decorrentes, verifica-se que diversos autores apontam a busca pela melhoria da qualidade de vida dessas pessoas como importante objetivo assistencial [24].

\subsubsection{O paciente com câncer cólon-retal.}

A problemática do adulto sobrevivente ao câncer cólon-retal, certamente exacerbada pela presença de um componente estigmatizante e mutilante como o estoma intestinal, associada à prática profissional, têm sido fontes de estímulo para aprofundar o conhecimento sobre a qualidade de vida desta clientela.

Inúmeras fantasias e metáforas giram em torno do diagnóstico de câncer, as quais o associam com a morte, sendo que nada consegue ser claro e bem definido para o homem no plano físico, tendendo a ser cercado por explicações psicológicas ou espirituais.

Para Ferreira [26], apud Sutherland (1981), a pessoa com câncer é submetida a uma forma severa e especial de estresse gerado pela ameaça da doença incapacitante ou da morte, da mutilação ou perda pela cirurgia de uma parte importante do corpo. Para Ferreira [26]:

" O simples fato de utilizarmos a palavra câncer para designar um conjunto de patologias tumorais já indica a necessidade da integração entre os vértices psicológicos e médicos, pois observamos um enorme conteúdo emocional ligado à idéia câncer em comparação com a informação científica câncer (...)" 
O mesmo autor [26] cita que sua pronúncia suscita, antes de uma idéia técnica, fantasias de dor, morte e sofrimento, com caráter persecutório tão evidente que é comum as pessoas negarem-se a pronunciá-la, substituindo-a por "aquela doença" como se ela evocasse uma entidade demoníaca de grande poder de destruição.

Para Casciato e Lowitz [27], a existência de um processo neoplásico altera virtualmente todos os aspectos da vida do paciente. A estabilidade emocional e manutenção do estilo de vida tornam-se bastante restrita. Apesar da magnitude, do stress e da mudança, a maioria dos pacientes encontram uma maneira de lidar com o fato de estar com câncer e receber uma terapêutica tóxica ou mutilante.

De acordo com Breckman [28], muitos pacientes, ao serem informados que sofrem de câncer, podem apresentar diferentes atitudes quanto à sua doença e mesmo imagem corporal. Isto varia de acordo com o conceito que o paciente tem sobre o câncer e seu prognóstico real e imaginário. Muita gente considera o câncer como uma enfermidade suja e anti-social, tem e que esta seja contagiosa e hereditária. Assim, não é estranho que pacientes que têm um câncer residual ou recorrente cheguem a expressar fantasia onde as células cancerígenas estão se movendo no interior do seu corpo, absorvendo-lhes a vida.

A pessoa ostomizada, ao se deparar com o estoma no pós-operatório, passa a lidar com esta nova realidade, quando são suscitados vários sentimentos, reações e comportamentos, diferentes e individuais.

Para Boccardo [29], o estoma é um agente agressivo que leva à sensação de perda de segurança e integridade. A alteração da imagem corporal poderá gerar mudanças no estilo de vida do cliente, em maior ou menor intensidade, dependendo 
dos seus conhecimentos e valores, pois a possibilidade de reelaborar as atitudes relacionadas à imagem corporal são imprescindíveis para o estomizado [30].

Deve-se considerar que o cuidado envolve o relacionamento interpessoal, constituído de atitudes humanas, que não podem ser previsíveis ou préestabelecidas como uma função essencialmente técnica, e que são influenciadas por fatores inerentes aos indivíduos envolvidos [31].

Nessa perspectiva, o cliente é compreendido sob as dimensões físico, psicológica, social e espiritual no peri-operatório.

Os aspectos físicos referem-se às questões da estomia propriamente dita. $\mathrm{O}$ indivíduo terá que conviver com a mudança fisiológica, na forma de eliminação das fezes e todas as implicações decorrentes desta alteração como o odor das fezes e o uso obrigatório de um dispositivo aderido ao abdome [32].

Segundo Andrade [33], apud Santos (1994), os problemas físicos mais freqüentes apresentados pelos pacientes estomizados são: preocupação com o aspecto do estoma e alterações do mesmo, alteração da integridade da pele periestoma, alterações na consistência das eliminações, alterações da atividade sexual e complicações do estoma.

Na fase pré-operatória e diagnóstica, o paciente é invadido por todos os medos, do próprio diagnóstico, da cirurgia, das possíveis seqüelas, da internação hospitalar, de ser rejeitado pela família e sociedade, sentimentos de mutilação e depressão também estão presentes.

O contato da equipe de saúde com os pacientes, no pré-operatório, permite um levantamento das necessidades de informações e preparo pré-operatório. Nessa ocasião deve-se dar alguma orientação sobre a provável localização, características e tipos de eliminação do estoma. É importante estabelecer um perfeito sistema de 
comunicação entre a equipe de saúde, paciente e familiares, a fim de que haja troca de informações corretas e coerentes, introduzindo atividades educacionais que possam, desde o início, prover segurança e independência para o autocuidado. Também é útil mostrar os tipos de bolsas, protetores e adesivos, técnica de colocação da bolsa, desde que isso se faça num momento psicologicamente adequado e atenda, exatamente, às demandas do paciente [33].

No pré-operatório procede-se à demarcação do estoma e, posteriormente, pode-se optar pela colocação de um dispositivo com característica e diâmetro semelhantes ao que será utilizado no pós-operatório imediato, afim de conferir a demarcação [34].

Problemas de ordem psicossocial também são comuns. O isolamento, muitas vezes motivado pela eliminação de odores e ruídos desagradáveis, leva à marginalização social, redução de atividades de lazer, perda da capacidade de conviver nos grupos sociais, conseqüências estas provocadas não somente a partir dos outros, mas, freqüentemente do próprio paciente. A presença de urina ou fezes num plano do corpo que pode ser visível (ou pelo menos detectável) para outros durante o contato social ou íntimo, leva a uma maior preocupação da pessoa com um estoma. Indivíduos com estomas têm conseqüências psicossociais, podendo acarretar insucesso no retorno às ocupações, havendo afastamento íntimo e social, depressão e ansiedade. Expressões negativas em relação à imagem corporal estão tipicamente associadas à ansiedade, submissão e insegurança [33].

Quanto aos aspectos psicológicos, uma das preocupações para o cuidado é com a alteração da imagem corporal, que leva à sensação e rejeição de si mesmo. A imagem corporal refere-se aos sentimentos quanto à maneira como nos percebemos, nossas reações ao mundo que nos circunda [35]. 
O processo de reinserção social de pessoas portadoras de estomias constitui o foco central do cuidado prestado pela equipe multidisciplinar inserido no contexto de reabilitação [29].

A reinserção social é um desafio para o estomizado na medida que a confecção de um estoma representa e supõe uma agressão à integridade física e psíquica com severas repercussões nos planos da imagem corporal e autoconceito [29].

Shilder [36], apud Tomaselli, define imagem corporal como a percepção que o indivíduo forma do seu prórpio corpo. Assim, o significado do estoma para o indivíduo, passa por diversas fases até a reconstrução de um nova identidade, com a incorporação dessa nova situação.

Cohen [37], descreve como primeiro estágio (fase pós operatória mais precoce) aquele em que o estoma é percebido pela paciente como uma doença, algo estranho e sem controle. No segundo estágio, o estoma constitui uma incorporação, isto é, tanto a identidade do indivíduo como a do estoma passam a se integrar em uma única identidade, uma parte legítima do estomizado.

O estoma é, portanto, muitas vezes o custo da saúde para o indivíduo, exigindo que ele desenvolva tal processo de reconstrução de identidade pessoal e reformulação de sua imagem corporal. Somente desta forma conseguirá atingir um nível adequado de reabilitação, voltando a assumir suas atividades pré-operatórias e pré-doença, mesmo com dificuldades, o mais próximo do normal possível [29].

Para tanto, o papel do enfermeiro é fundamental como elemento de uma equipe, na medida que o auxilia a tornar-se independente através da reaquisição da sua autonomia para manter sua dignidade e voltar a desenvolver a sua auto-estima [29]. 
A imagem do corpo, a imagem internalizada que o indivíduo tem de sua própria aparência física, é um aliado importante para sua autoconcepção. Mudanças ou distúrbios na imagem do corpo podem afetar negativamente a própria concepção sexual [33].

Colostomizados que sofrem cirurgia para retirada de carcinoma retal, relatam a impotência como um grande problema, comparativamente à fase anterior. Em muitos casos, eles acham que o tratamento muda a estabilidade do casamento. Por exemplo, a mulher pode sentir que seu marido perde a afeição por ela, porque ele se torna impotente. Outros colostomizados revelam que ficam embaraçados durante a relação sexual pela presença da bolsa, pelo desconforto ou à mudança de posição. Essa percepção do estomizado, com relação ao parceiro, pode levá-lo a isolar-se [33].

Andrade et al [33], apud Thompson (1994), que estudou ileostomizados, afirma que em $19 \%$ deles, a função sexual cessou após a cirurgia de confecção de ileostomia. Muitos indicam como aspectos negativos nas relações com a família e parceiros, o nojo, com conseqüente isolamento e diminuição da espontaneidade e redução da nudez.

No estudo de Andrade et al [33], sobre a sexualidade do estomizado na visão do parceiro, considerando os aspectos físicos, psicológicos e sociais que possam interferir nas relações interpessoais, foram elaboradas algumas suposições, não permitindo estabelecer conclusões e reflexões acerca da qualidade de vida dos casais frente às alterações na esfera da sexualidade. Foi constatado queda na qualidade de vida, em conseqüência das mudanças na sexualidade dos estomizados, apontados pelos parceiros, dirigida principalmente pela diminuição ou ausência de relações sexuais. 
Os problemas sociais podem decorrer da insegurança causada pela qualidade dos materiais e equipamentos utilizados. Muitas vezes o paciente pode se sentir vulnerável e isolar-se tanto do convívio familiar quanto social [32].

A experiência do colostomizado/ileostomizado vai se transformando ao longo do tempo. Logo nos primeiros dias de pós-operatório, este não consegue nem mesmo olhar para o estoma ou elaborar seus sentimentos ou reações para esta realidade [31].

Com o decorrer do tempo, dependendo da evolução da sua doença e as possibilidades de adaptação encontradas, o estomizado desenvolve estratégias de enfrentamento com as quais passa a lidar com os problemas ou modificações cotidianas ocorridas em função da estomia. Assim, a pessoa necessita de um tempo pessoal para refletir e adaptar-se à sua condição de estomizado, que pode levar dias, semanas ou meses [31].

Shipes [37], apud Andrade et al (1997), relata que as reações dos membros da família em relação à cirurgia de estomia e o impacto dessas reações no ajustamento, revelam que o paciente se adapta melhor e se sente menos isolado quando a família é incluída no plano de ensino e cuidado. Assim sendo, o suporte familiar torna-se vital para a adaptação psicossocial do estomizado; tendo não só o enfermeiro como toda a equipe de saúde, a incumbência de incluir a família no plano de cuidado, em todas as áreas. A reabilitação do estomizado inclui o preparo para lidar com seus medos, fantasias, ansiedades e aceitá-los como seres humanos capazes de se reintegrar, mesmo que lentamente, às suas condições prévias de vida.

As inúmeras complicações estomais e paraestomais surgem da precária localização do estoma, estão associadas a outros fatores de ordem mais geral como 
idade, fragilidade da musculatura abdominal, aumento de peso no pós-operatório entre outros [34].

Todavia, situar o estoma numa área que assegure a aderência do dispositivo e que facilite a manipulação do paciente, constitui-se em estratégia de prevenção de complicações importantes [34].

As formas de tratamento do câncer são geralmente agressivas, implicando em ameaça séria à integridade do organismo e de sua função, além de afastar o indivíduo dos seus familiares e amigos, tanto pela necessidade de longos e freqüentes períodos de internação para tratamento, como também pela própria concepção cultural do câncer que leva ao isolamento e abandono [26].

Sousa apud Hashimoto et al [38] consideram o estoma como algo que modifica a imagem corporal, resultando em mutilação com alterações funcionais dos órgãos de eliminação com alterações anatômicas e principalmente comportamentais dos indivíduos. Desta forma, os indivíduos estomizados desenvolvem alterações de ordem física, psicológica e social que certamente influenciam na qualidade de vida. Na esfera física, são observados distúrbios intestinais, sexual (ereção e ejaculação prejudicada, dispareunia), restrições alimentares e cuidados com a pele periestoma. As alterações na esfera psicossocial caracterizam-se pela imagem corporal alterada, isolamento social, redução das atividades de lazer e trabalho.

Frente ao exposto, justificamos o nosso interesse em avaliar a qualidade de vida do estomizado secundário ao câncer cólon-retal. 


\subsection{Qualidade de vida de indivíduos com estoma intestinal}

Sobre as definições de qualidade de vida, pode-se afirmar que elas são tão numerosas quanto os métodos de avaliá-las e que não existe consenso sobre o seu significado [20]. No entanto, existe consenso nas principais características do construto de qualidade de vida que são: a subjetividade, multidimensionalidade e bipolaridade; um outro aspecto importante encontra-se no dinamismo que envolve esse conceito e a influência que a cultura exerce sobre o significado de qualidade de vida.

O grupo de Qualidade de Vida da divisão de Saúde Mental da OMS define Qualidade de Vida como "a percepção do indivíduo de sua posição na vida no contexto da cultura e sistema de valores nos quais ele vive e em relação aos seus objetivos, expectativas, padrões e preocupações" [39].

A revisão bibliográfica sobre qualidade de vida mostra uma crescente preocupação com o tema nas últimas décadas do século passado e muitos autores têm voltado suas pesquisas não somente para a promoção da saúde, mas para como pesquisar a qualidade de vida, considerando que esta é marcada por valores subjetivos [40].

Embora existam na literatura vários outros conceitos e definições sobre qualidade de vida, algumas propriedades do construto ficam estabelecidas, como a subjetividade, a transculturação, a multidimensionalidade, a polissemia, a variabilidade no tempo e os elementos de auto-avaliação, tanto positivos quanto negativos [41].

Na área da saúde, deve-se ressaltar que o conceito qualidade de vida ganhou importância, nos últimos anos, especialmente após as grandes guerras do século 
XX, e contemporaneamente à definição de saúde estabelecida pela OMS, em 1947, como "um estado de bem-estar físico, mental e social e não somente ausência de doença" [42].

Atualmente, as questões que se impõem, na área da saúde, referem-se a estabelecer se os tratamentos resultam numa vida de melhor qualidade e não apenas em uma vida mais longa, e a pautar a tomada de decisões na coresponsabilidade de profissionais e clientela [43].

A qualidade de vida passa do âmbito da saúde quando se considera que a doença e as intervenções realizadas pelos profissionais influenciam tanto a quantidade (sobrevivência) como a qualidade da vida do indivíduo [42].

A visão de qualidade de vida em saúde, segundo Farquhar [44], pode ser avaliada em termos individuais ou ser estendida a uma visão mais ampla, incluindo a família e até mesmo a comunidade.

Katz [45] referencia que a questão de interesse na ciência atual, é verificar se o avanço tecnológico utilizado no tratamento de clientes crônicos permite uma melhor qualidade de vida ou se resulta somente no prolongamento da vida. O autor admite que a eficácia do tratamento deve ser mensurada também em termos de qualidade de vida do cliente.

A mensuração da qualidade de vida dos clientes pelos serviços de saúde tem buscado avaliar a eficácia e cobertura destes em relação às suas clientelas. Em cirurgia, os estudos acerca da qualidade de vida estão sendo utilizados para avaliar o sucesso do procedimento cirúrgico e seus resultados na vida do cliente, ou seja, a capacidade de reintegração desse cliente à sua vida ativa normal [46].

Cella [47] propõe que, ao serem submetidos à cirurgia, os clientes deveriam expor suas esperanças, propostas e metas diante do tratamento, podendo assim 
avaliar seu potencial para recuperação e o impacto da cirurgia em sua qualidade de vida. Dentro dessa perspectiva as cirurgias que resultam em estomas, classificadas como mutiladoras por trazerem modificações na imagem corporal, deveriam passar previamente por um processo de aceite do cliente, pois, segundo Brekman [28], uma das principais preocupações do cliente antes e após a cirurgia é saber se seu estilo de vida vai ser alterado pela presença do estoma.

Tradicionalmente, no caso específico do doente com câncer, os objetivos dos tratamentos têm sido reduzir os sintomas e prolongar a vida. Entretanto, o tempo de sobrevivência nada informa sobre a qualidade da vida desse indivíduo ao serem consideradas as conseqüências pessoais e sociais do tratamento e da própria doença.

No contexto da oncologia, a qualidade de vida é definida como a percepção subjetiva do indivíduo em relação à sua incapacidade e à satisfação com seu nível atual de funcionamento, o que faz com que a pessoa considere que esteja bem ou não, comparativamente ao que percebe como possível ou ideal [47].

De acordo com Bowling [48], muitos estudos de qualidade de vida em oncologia limitam a sua definição e mensuração nos aspectos do sintoma, funcionamento físico e bem estar psicológico. Ressalta também que o foco principal na área médica recai sobre a sobrevivência, recorrência, sobrevivência livre da doença, sintomas, toxicidade do tratamento, resposta do tumor ao tratamento e tempo de resposta.

Considerando que o paciente oncológico apresenta alterações nas várias esferas de sua vida, ou seja, nos aspectos físicos, emocionais e sociais, concordamos com Santos [49] que recomenda que para avaliar a qualidade de vida de pacientes com câncer é necessário incluir os aspectos de bem estar físico 
(sintomas e toxicidade do tratamento), bem estar psicológico (imagem corporal, auto-estima, estresse, depressão) e bem estar social (isolamento, suporte social e familiar).

Em relação aos instrumentos de avaliação de terapias no câncer, foram encontrados vários instrumentos na literatura internacional: Symptom distress scale desenvolvido por McCorkle e Young em 1978, Lary Sexual functioning scale for Breast Câncer patients por Lasry et al em 1987, Macgill Náusea questionnaire por Melzack em 1985; Medical Research Council uk sacale por Fayers e Jones em 1987; EORTC desenvolvido por Aaronson et al em 1986; Rotterdan symptom checklist por HAes et al em 1986; Functional Living index Cancer (FLIC) por Schipper et al em 1989, Functional Living Index emesis (FLIE) por Lindley et al em 1992, Cancer invectory of problem situations( CIPS) and the cancer reablitation System( CARE) por Schag et al em 1983; Heirch et al em 1884; Spitzer Quality of life index por Spitzer et al em 1981; Linear Analogue Self-assessment Scale (LASA) por priestman e Baum em 1976; Ontario Cancer Institute/ Royal Marsdsen LASASacale por Selben et al em 1984; Padilla Quality of Life Scale and Variants, including the Multidimensional Quality of Life Scale Câncer (MQOLS-Ca) por PAdilla et al em 1981; Holmes and Dickerson Scale por Holmes e Dickerson em 1987; Global Quality of life Scale (COATES) por Coates et al em 1990; Quality of Life index por feFerrans e Powers em 1985; Cancer Rehabilitation Evaluation System, Functional Assessment of Cancer Therapy e European Organization for Research and Treatment of Cancer Core Quality of Life Questionnaire.

Em nossa revisão de literatura encontramos dois instrumentos específicos para a avaliação de qualidade de vida de portadores de câncer cólon-retal: Functional Assessment of Cancer Therapy Scales for Colorectal Câncer (FACT-C), e 
European Organization for Research and Treatment of Cancer Colorectal Specific Quality of Life Questionnaire Module (EORTC QLQ-C38), porém ainda não adaptados para a língua portuguesa. A importância de utilizarmos instrumentos previamente validados em nossa cultura para a obtenção de dados fidedignos fez com que escolhessemos o EORTC QLQ-C30, já adaptado para a língua portuguesa por Brabo [50] e a escala de Qualidade de Vida de Flanagan, adaptado por Hashimoto et al [38].

A escolha desses instrumentos objetivou medir a qualidade de vida em vários aspectos e domínios já que nenhum instrumento satisfaz um modelo multidimensional completo de qualidade de vida. A escala de qualidade de vida de Flanagan é um instrumento genérico de avaliação de qualidade de vida e o “European Organization for Research and Treatment of Cancer Core Quality of Life Questionnaire"- Organização Européia de Pesquisa e Tratamento do Câncer (EORTC-QLQ-C30), instrumento específico que avalia a qualidade de vida do portador de cancer. O uso de instrumentos genéricos e específicos é recomendado por Kerr et al [51], que considera que os instrumentos genéricos avaliam um perfil de saúde geral e os específicos revelam características específicas das doenças, por isso são complementares e devem ser empregados concomitantemente para obtenção de maior número de dados.

A escala de qualidade de vida de Flanagan (EQVF), foi proposta e desenvolvida por este autor em 1978, estudando 3000 homens e mulheres da população geral norte-americanos. A escala original de Flanagan foi traduzida para mais de 16 línguas, inclusive o português. No Brasil, os autores que a traduziram não fizeram referência quanto à fidedignidade da versão em português. A pesquisa de Nassar \& Gonçalves [52] que utilizou a Escala de 
Flanagan, na população brasileira, revelou um alpha de cronbach $=0,88$ demonstrando consistência interna.

Em 1986, a Organização Européia de Pesquisa e Tratamento do Câncer (EORTC) iniciou um programa de pesquisas visando desenvolver um instrumento para avaliar a qualidade de vida (QV) de indivíduos com câncer O instrumento foi denominado de QLQ-C30, sendo disponível em três versões. A primeira é de 1987 e contém 36 questões, a segunda é de 1993 e a terceira, de 2000, contém 30 questões.

O EORTC QLQ-C30 (versão 3.0), a ser utilizado neste estudo, é um questionário contendo 30 itens composto por escalas com múltiplos itens e medidas de item único que visam refletir a multidimensionalidade do construto qualidade de vida.

No Brasil, o questionário foi validado por Brabo [50], Santos [53] utilizou o EORTC QLQ C-30 para analisar a qualidade de vida de pacientes com câncer cólonretal tratados com intenção curativa. Nesse estudo encontrou consistência interna das escalas do EORTC QLQ C-30, sendo que em cinco das escalas o coeficiente alpha de Cronbach foi acima de 0,70 , na escala função social o coeficiente alpha foi de 0,69 e nas de sintomas fadiga e náuseas e vômitos o alpha de Cronbach variou de 0,47 a 0,57 . 
2-OBJ ETIVOS 


\subsection{Objetivo Geral}

- Investigar a qualidade de vida do paciente com estoma intestinal secundário ao câncer cólon-retal.

\subsection{Objetivos Específicos}

- Identificar as características sociais e clínicas da clientela portadora de estoma intestinal secundário ao câncer cólon-retal.

- Identificar os domínios da qualidade de vida afetados nos clientes com câncer cólon-retal.

- Relacionar os dados sócio-demograficos e clínicos com a qualidade de vida.

- Correlacionar os dados dos instrumentos utilizados, EORTC-C30 e Flanagan. 
3-METODOLOGIA 
O estudo do paciente estomizado e sua qualidade de vida implica em resgatar necessariamente essa relação, tendo por base uma realidade concreta e um determinado olhar, o que remete uma opção metodológica. Assim, escolheu-se realizá-lo em formato descritivo-exploratório, na vertente quantitativa.

As pesquisas exploratórias têm como principal finalidade desenvolver, esclarecer e modificar conceitos e idéias, com vistas na formulação de problemas mais precisos ou hipóteses pesquisáveis para estudos posteriores. De todos os tipos de pesquisa, estas são as que apresentam menor rigidez no planejamento. Habitualmente envolvem levantamento bibliográfico e documental, entrevistas não padronizadas e estudos de caso [41].

Muitas vezes as pesquisas exploratórias constituem a primeira etapa de uma investigação mais ampla. Quando o tema é bastante genérico, tornam-se necessários seu esclarecimento e delimitação, o que exige revisão da literatura, discussão com especialistas e outros procedimentos. O produto final deste processo passa a ser um problema mais esclarecido, possível de investigação mediante procedimentos mais sistematizados [41].

Nesta vertente, optou-se pela coleta de dados através de entrevista, utilizando-se um instrumento contendo três partes, uma primeira com dados sóciodemográficos acerca do cliente (Anexo 2), uma segunda com itens referentes à Escala de Qualidade de Vida de Flanagan (1982) (Anexo 3), e um terceiro instrumento de qualidade de vida proposto pela European Organization for Research and Treatement of Cancer Quality of Life Questionnaire (EORTC- QLQ-C-30) (Anexo 4). 


\subsection{Amostra}

No período entre 2001 a 2005 foram admitidos no Centro de Oncologia Dr Osvaldo Leite, 3058 pacientes com câncer, destes, 75 apresentavam câncer de localização cólon-retal. Do total de 75 pacientes, foram entrevistados 20, no período de janeiro de 2005 a dezembro de 2005, 2 foram excluídos pois não foi preenchido o Termo de Consentimento Livre e Esclarecido por recusa dos mesmos. Portanto, a amostra constou de 18 pacientes.

Os critérios de inclusão foram: pacientes estomizados secundários ao câncer cólon-retal, operados no período de 2001 a 2005; idade igual e/ou superior a 18 anos, residentes dentro do estado de Sergipe, em razão dos custos dos contatos presenciais necessários para a coleta de dados e assinaturas do consentimentos livre e esclarecido da pesquisa.

Adotamos como critérios de exclusão: pacientes com síndromes demenciais e/ou outras condições que os impeçam de compreender e responder os questionários; pacientes sem seguimento/acompanhamento médico.

\subsection{Local de estudo}

A pesquisa foi desenvolvida no Centro de Oncologia $\operatorname{Dr}$ Oswaldo Leite, unidade integrante da estrutura organizacional do Hospital Governador João Alves Filho, localizado na cidade de Aracaju - Sergipe.

O Centro de Oncologia Dr Oswaldo Leite, é um Centro de Alta Complexidade em Oncologia (CACON), designado para proceder diagnóstico, tratamento e seguimento de pacientes com câncer, adultos e crianças de forma interdisciplinar. 
Foi inaugurado em 2002, mas antes desta data, já havia atendimento a pacientes oncológicos. Atualmente possui 49 (quarenta e nove) leitos, sendo 21 (vinte e um) destinados ao atendimento de crianças e 28 (vinte e oito) destinados ao atendimento de pacientes adultos.

\subsection{Procedimentos para coleta de dados}

Após a aprovação do Projeto de Pesquisa, pela Diretoria de Saúde $^{1}$ da Instituição, os pacientes foram selecionados através dos seguintes passos: levantamento do tipo de cirurgias, nome completo do paciente, data e nome do médico cirurgião junto ao livro de registros do Centro Cirúrgico e setor de internação da oncologia, dados estes registrados pela secretária de cada setor. Após coleta dos dados dos pacientes, foram solicitados os números dos prontuários para que estes fossem encontrados nos arquivos do Centro de Oncologia; este dado foi fornecido pela agente administrativa do mesmo, encontrado no sistema de cadastramento informatizado, porém, alguns dos pacientes não foram encontrados, pois não tinham cadastro. Este processo foi um dos agentes dificultadores para coleta de dados, demonstrando a necessidade de um sistema de busca de dados mais bem estruturado.

Os registros dos prontuários foram consultados para determinar as características sócio-demográficas e clínicas. Após verificação dos critérios de inclusão e exclusão, o paciente foi convidado a participar do estudo através do contato telefônico, onde foram agendados data, hora e local da entrevista e

\footnotetext{
${ }^{1}$ O projeto foi aprovado pela Diretoria de Saúde, que faz o papel do Comitê de Ética
} e Pesquisa da instituição investigada. 
assinatura do Termo Consentimento Livre e Esclarecido. Durante a entrevista foram preenchidos os seguintes instrumentos:

- Formulário contendo características sócio-demográficas e clínicos: sexo, idade, estado civil, procedência, estado, diagnóstico, presença de metástase, data da confecção do estoma e complicações presentes (Anexo 2).

- Instrumentos para avaliação da Qualidade de vida: Escala de qualidade de vida de Flanagan e EORTC QLQ-C30 (Anexo 3 e 4).

Para a análise dos instrumentos utilizou-se o Programa SPSS/PC for Windows [54].

\subsection{Descrição dos Instrumentos para avaliação da Qualidade de vida}

\subsubsection{Escala de Qualidade de Vida de Flanagan}

A escala de Qualidade de Vida de Flanagan inclui 15 componentes ou domínios, enquadrados em cinco dimensões: Dimensão 1 - bem-estar físico e material (conforto material e saúde), Dimensão 2 - relações com outras pessoas (pais, irmãos e outros parentes, ter e criar filhos, relacionamento íntimo e amigos próximos), Dimensão 3 - atividades sociais, comunitárias e cívicas (ajuda voluntária

e participação em associações), Dimensão 4 - desenvolvimento pessoal e realização (aprendizagem, auto-conhecimento, trabalho e comunicação criativa), Dimensão 5 - recreação (socialização, participação em recreação passiva e ativa). Nesta versão, todos os itens são respondidos através de uma escala do tipo Likert de 7 pontos $(1$ = extremamente insatisfeito, 2 = bastante insatisfeito; 3 = insatisfeito; 
4 = indiferente (nem satisfeito nem insatisfeito); 5 = satisfeito; 6 = bastante satisfeito; 7 = extremamente satisfeito). $O$ range potencial variou de 15 a 105 pontos, também na versão em português.

Para uma melhor compreensão de nossa clientela acerca do valor dado a cada item, resolveu-se unir os itens 2 e 3 da Escala de Flanagan (1982), traduzida por Hashimoto et al [38], deixando a escala em seis itens, conforme trabalho realizado por Souza [55], dando outros sinônimos aos acima citados, ficando da seguinte maneira: (1) ruim, (2) regular, (3) indiferente, (4) bom, (5) muito bom, (6) ótimo.

O range potencial de EQVF pode variar de 6 a 90 pontos, os domínios podem variar de acordo com a quantidades de questões incluídas. Assim os Domínio 1 e 3 possuem um range potencial de 2 a 12, o Domínio 2 possui um range potencial de 4 a 24 e o Domínio 5 de 3 a 18.

\subsubsection{European Organization for Research and Treatment of Câncer Quality of Life Questionnaire “Core" 30-Items (EORTC-QLQ-C30) versão 3.0 em português.}

O EORTC QLQ-C30, inclui cinco escalas funcionais: função física, cognitiva, emocional, social e desempenho de papéis. Três escalas de sintomas: fadiga, dor,náuseas e vômitos. Uma escala de qualidade de vida e saúde global. Seis outros itens que avaliam sintomas comumente relatados por doentes com câncer: dispnéia, falta de apetite-anorexia, insônia, constipação e diarréia. Escala de avaliação de impacto financeiro do tratamento e da doença [56]. 
Os escores das escalas e das medidas dos itens individuais variam de 0 a 100 , sendo que um alto valor do escore representa uma alto nível de resposta. Ou seja, um alto escore para a escala funcional representa um nível funcional saudável, já um escore alto para a escala de sintomas/itens representa um alto nível de sintomatologia/problemas [56].

O princípio para determinar os escores das escalas é o mesmo em todos os casos [56].

Estabelece-se um escore bruto (EB) de cada escala, que é formado pelo somatório do valor das alternativas assinaladas em cada questão/item que compõe a escala, e dividido pelo número de respostas. O valor das alternativas variam de 1 a 4, da questão 1 a 28 :

$$
E B=q 1+q 2+q 3 \ldots \ldots . . q n / n
$$

Sendo que $\mathrm{n}$ é o número total dos itens que compõem a escala ou item individual.

Exemplo: função física.

$$
E B=q 1+q 2+q 3 \ldots \ldots \ldots q n / n
$$

O segundo passo é a transformação linear( escore entre 0 a 100), que deve seguir os seguintes passos:

-Cálculo para as Escalas Funcionais:

Escore $=[($ EB-1)/variação $] \times 100$

-Cálculo para a escala Global - EGS/QV:

Escore $=[($ EB-1)/variação $] \times 100$.

-Cálculo para as escalas/itens sintomas: 
Escore $=[($ EB-1)/variação $] \times 100$.

O quadro 1 apresenta a estrutura do EORTC QLQ-30. 


\begin{tabular}{|c|c|c|c|c|c|}
\hline & & \multicolumn{2}{|c|}{ Número } & \multicolumn{2}{|c|}{ Definição } \\
\hline Escalas * & Questões & Item & Níveis** & $\begin{array}{l}\text { Escore mínimo }=0 \\
\text { (floor) }\end{array}$ & $\begin{array}{c}\text { Escore máximo }=100 \\
\text { (celling) }\end{array}$ \\
\hline \multicolumn{6}{|c|}{ Medida Global de Saúde/QV } \\
\hline EGS/QV & 29 e 30 & 2 & 6 & $\begin{array}{l}\text { Condição física e qualidade de } \\
\text { vida ruins. }\end{array}$ & $\begin{array}{l}\text { Condição física e qualidade de } \\
\text { vida excelentes. }\end{array}$ \\
\hline \multicolumn{6}{|c|}{ Escalas Funcionais } \\
\hline FF & 1 a 5 & 5 & 3 & $\begin{array}{l}\text { Confinado a cama, necessita } \\
\text { de ajuda para tomar banho, } \\
\text { vestir-se e comer. }\end{array}$ & $\begin{array}{l}\text { Pode realizar atividades físicas } \\
\text { pesadas sem dificuldade. }\end{array}$ \\
\hline DP & 6 e 7 & 2 & 3 & $\begin{array}{l}\text { Impedido de trabalhar ou } \\
\text { realizar atividades de lazer. }\end{array}$ & $\begin{array}{l}\text { Não apresenta limitações no } \\
\text { trabalho ou lazer. }\end{array}$ \\
\hline FE & 21 a 24 & 4 & 3 & $\begin{array}{l}\text { Sente-se muito tenso, irritado, } \\
\text { deprimido e preocupado. }\end{array}$ & $\begin{array}{l}\text { Não se sente tenso, irritado, } \\
\text { deprimido e preocupado. }\end{array}$ \\
\hline $\mathrm{FC}$ & 20 e 25 & 2 & 3 & $\begin{array}{l}\text { Apresenta muita dificuldade } \\
\text { em concentrar-se e recordar } \\
\text { informações. }\end{array}$ & $\begin{array}{l}\text { Não apresenta dificuldades de } \\
\text { concentração e memória. }\end{array}$ \\
\hline \multirow[t]{2}{*}{ FS } & 26 e 27 & 2 & 3 & A condição física e $\quad 0$ & A condição física e o tratamento \\
\hline & & & & $\begin{array}{l}\text { tratamento interferem muito na } \\
\text { vida familiar e em atividades } \\
\text { sociais. }\end{array}$ & $\begin{array}{l}\text { não interferem na vida familiar e } \\
\text { nas atividades sociais. }\end{array}$ \\
\hline \multicolumn{6}{|c|}{ Escalas de Sintomas } \\
\hline FAD & $\begin{array}{l}10,12 \text { e } \\
18\end{array}$ & 3 & 3 & $\begin{array}{l}\text { Não se sente cansado ou } \\
\text { fraco e não necessita } \\
\text { Descansar }\end{array}$ & $\begin{array}{l}\text { Sente-se muito fraco, cansado e } \\
\text { necessita descansar a maior } \\
\text { parte do tempo. }\end{array}$ \\
\hline NAV & 14 e 15 & 2 & 3 & $\begin{array}{l}\text { Não apresenta náuseas ou } \\
\text { vômitos. }\end{array}$ & $\begin{array}{l}\text { Sente-se muito nauseado e } \\
\text { vomita muito. }\end{array}$ \\
\hline Dor & 9 e 19 & 2 & 3 & Não sente dor. & Apresenta muita dor que \\
\hline & & & & & interfere em todas as atividades. \\
\hline \multicolumn{6}{|c|}{ Sintomas (Itens) } \\
\hline DIS & 8 & 1 & 3 & Não apresenta dispneia. & Apresenta dispneia severa. \\
\hline INS & 11 & 1 & 3 & $\begin{array}{l}\text { Não tem dificuldades para } \\
\text { dormir. }\end{array}$ & Não consegue dormir. \\
\hline PAP & 13 & 1 & 3 & Apetite conservado. & Anorexia severa. \\
\hline CON & 16 & 1 & 3 & Sem constipação. & Constipação severa. \\
\hline DIA & 17 & 1 & 3 & Sem diarreia. & Diarreia Severa. \\
\hline \multicolumn{6}{|l|}{ Item } \\
\hline DIF & 28 & 1 & 3 & $\begin{array}{l}\text { A condição física e o tratamento } \\
\text { não provocam dificuldades } \\
\text { financeiras. }\end{array}$ & $\begin{array}{l}\text { A condição física e o } \\
\text { tratamento provocam muitas } \\
\text { dificuldades financeiras. }\end{array}$ \\
\hline
\end{tabular}

* Siglas das Escalas: EGS/QV = Estado Gerai de Saúde/ QV; FF = Função Física; DP = Desempenho de Papel; FE = Função Emocional; FC = Função Cognitiva; FS = Função Social; FAD = Fadiga; NAV = Náuseas e Vómitos; DIS = Dispneia; INS = Insónia; PAP = Perda de Apetite; COM = Constipação; DIA = Diarreia; DIF = Dificuldades Financeiras. ${ }^{* *}$ Diferença entre a maior e a menor resposta possível de cada item.

Quadro 1 - Escalas e Itens do EORTC QLQ-C30, questões correspondentes, número de itens e variação de cada item. 


\subsection{Análise estatística dos dados}

\subsubsection{Métodos para validação dos instrumentos para Avaliação da Qualidade de Vida}

Os métodos utilizados para verificar a adequação dos instrumentos em relação à amostra estudada foram parte dos métodos empregados para avaliar a confiabilidade da Escala de Qualidade de Vida de Flanagan. Foi verificada a consistência interna das escalas através do Coeficiente alfa de Cronbach.

Além do cálculo do coeficiente de correlação do item com a escala a que pertence, foram calculados o coeficiente de correlação de cada item com as outras escalas do instrumento. Assim, verifica-se a validade discriminativa do item, ou seja, o item deve apresentar correlação maior com a escala a que pertence do que com as demais escalas.

\subsubsection{Verificação da associação entre as escalas dos Instrumentos para} Avaliação da Qualidade de Vida e as variáveis sócio demográficas e clínicas.

As variáveis dos dados socio-demográficos e clínicos são apresentados após análise estatística descritiva através do cálculo da média, desvio-padrão; e análise inferencial, através dos seguintes procedimentos estatísticos: intervalos de confiança de $95 \%$, usados para estimar o valor médio real das variáveis quantitativas e porcentagens reais de alguns eventos de interesse do estudo; Teste $t$-student utilizado para a comparação entre as médias de variáveis das escalas; coeficiente de Correlação Linear de Pearson usado na avaliação das correlações, entre 
variáveis numéricas contínuas; e Análise de Regressão Linear Múltipla, usada para avaliar quais variáveis permaneceram estatística e independentemente associadas com as questões que avaliam qualidade de vida geral.

Os escores da escala de Qualidade de Vida de Flanagan e EORTC QLQ-C30, foram submetidos aos seguintes tratamentos estatísticos: Intervalo de Confiança de 95\% para estimação dos valores médios das variáveis quantitativas dos eventos de interesse; o Teste de Normalidade de Kolmogorov-Smirnov, para testar a hipótese de normalidade das variáveis quantitativas do estudo. Entretanto, uma vez que todos os domínios desta escala apresentaram nível de significância superior a 5\%, ou seja, aceitando a hipótese de normalidade, foram utilizados testes paramétricos: t-student e Análise de variância (ANOVA). O Coeficiente de Correlação Ordinal de Spearman para a avaliação da correlação entre as variáveis quantitativas; o Coeficiente de Correlação Linear de Pearson para a avaliação da correlação ordinal por ponto das variáveis respostas e as variáveis qualitativas dicotomizadas.

No instrumento de qualidade de vida EORTC QLQ-C30, não foram utilizados os coeficientes de correlação de Spearman e Pearson.

Para este estudo, adotou-se $\mathrm{P}$ value inferior a 0,05 como estatisticamente significante.

\subsubsection{Validação dos instrumentos para avaliação da Qualidade de Vida}

Considerando-se alguns fatores como o caráter genérico da EQVF, a especificidade da clientela portadora de câncer cólon-retal e estoma e a recomendação de alguns pesquisadores envolvidos com os estudos de qualidade de vida, procedeu-se à validação da EQVF para este estudo, através da avaliação 
de sua consistência interna mediante os Coeficientes Alfa de Cronbach, cujos resultados estão no quadro 2.

A confiabilidade é a primeira característica que um instrumento deve possuir e é definida como o grau de coerência e precisão com que determinado instrumento mede o atributo que está se propondo a medir, sendo mais frequentemente avaliada através da consistência interna, utilizada neste estudo. A consistência interna do instrumento foi verificada quanto aos domínios, facetas e cada domínio individualmente através do Coeficiente de fidedignidade Alpha de Cronbach, que trabalha a relação entre covariâncias e variâncias internas das medidas, partindo da premissa de que as correlações são sempre positivas. Os valores Alpha de Cronbach variam de 0 a 1 e quanto maior o coeficiente, maior consistência interna e homogeneidade dos itens, o que indica a acurácia da medida.

\begin{tabular}{|l|c|c|}
\hline \multicolumn{1}{|c|}{ Escala/ Item } & $\mathrm{N}^{\circ}$ items & $\begin{array}{c}\text { Coeficiente alfa de } \\
\text { Cronbach }\end{array}$ \\
\hline EQVF (Dimensões) & 5 & 0,823 \\
\hline Domínio 1 & 02 & 0,874 \\
\hline Domínio 2 & 04 & 0,664 \\
\hline Domínio 3 & 02 & 0,876 \\
\hline Domínio 4 & 04 & 0,778 \\
\hline Domínio 5 & 03 & 0,901 \\
\hline
\end{tabular}

Quadro 2 - Coeficientes Alfa de Cronbach das escalas do questionário de Qualidade de Vida de Flanagan e Dimensões.

O coeficiente alfa de Cronbach excedeu 0,70 em todas as escalas da EQVF, exceto o Domínio 2, sobre Relacionamento com outras pessoas, o que possibilita a sua utilização para a comparação entre grupos. 
O quadro 3 demonstra os testes de consistência interna das escalas do EORTC QLQ-C30.

\begin{tabular}{|lc|}
\hline \multicolumn{1}{|c|}{ Escala/ Item } & $\begin{array}{c}\text { Coeficiente alfa de } \\
\text { Cronbach }\end{array}$ \\
\hline Função Física & 0,89 \\
\hline Desempenho de Pessoal & 0,92 \\
\hline Função Emocional & 0,76 \\
\hline Função Cognitiva & 0,61 \\
\hline Função Social & 0,54 \\
\hline Dor & 0,34 \\
\hline Fadiga & 0,90 \\
\hline Náusea e vômito & 0,77 \\
\hline Estado Geral de Saúde/ QV & 0,40 \\
\hline EORTC QLQ-C30 geral & 0,90 \\
\hline
\end{tabular}

Quadro 3- Coeficiente alfa de Cronbach das escalas do questionário de qualidade de vida EORTC QLQ-C30.

No questionário EORTC QLQ-C30 do total de nove escalas, cinco apresentaram Coeficiente Alfa de Crobach acima de 0,70 (Quadro 2): Função física, desempenho de pessoal, função emocional, fadiga e náusea e vômito. As escalas função cognitiva, função social, dor e estado geral de saúde apresentaram coeficiente menor que 0,70.

No Quadro 4 os resultados dos coeficientes de consistência interna das escalas do instrumento EORTC QLQ-C30, observadas neste estudo, são comparados com outros estudos que empregaram este instrumento. 


\begin{tabular}{|c|c|c|c|c|c|c|c|c|c|c|}
\hline Autor & Tipo de Tumor & \multicolumn{9}{|c|}{ Escalas } \\
\cline { 3 - 11 } & & FF & DP & FE & FC & FS & FAD & NAV & DOR & EGS/QV \\
\hline $\begin{array}{c}\text { Santos } \\
{[54]}\end{array}$ & Cólonrretal & 0,72 & 0,81 & 0,75 & 0,57 & 0,69 & 0,47 & 0,56 & 0,87 & 0,76 \\
\hline $\begin{array}{c}\text { Apolone } \\
\text { et al [63] }\end{array}$ & $\begin{array}{c}\text { Cólon-retal e } \\
\text { mama }\end{array}$ & 0,64 & 0,85 & 0,87 & 0,77 & 0,83 & 0,85 & 0,58 & 0,82 & 0,9 \\
\hline $\begin{array}{c}\text { Amostra } \\
\text { atuall }\end{array}$ & Cólon-retal & 0,89 & 0,92 & 0,76 & 0,61 & 0,54 & 0,34 & 0,90 & 0,77 & 0,40 \\
\hline
\end{tabular}

Quadro 4 - Comparação dos resultados de consistência interna das escalas do EORTC QLQ-C30.

Analisando-se outros resultados da literatura, percebeu-se que os coeficientes função física, desempenho de pessoal, função emocional, função cognitiva e dor foram semelhantes à amostra atual. As escalas função social, fadiga e estado geral de saúde demonstraram-se pouco confiáveis quando comparados com dados da literatura, descrito no quadro 3. Destacou-se a escala náusea e vômito, onde a consistência interna foi menor que 0,60 nos trabalhos apresentados, e na amostra atual foi igual a 0,90.

O alto coeficiente da escala náusea e vômito pode ser atribuído ao fato de que esta amostra é composta por pacientes em tratamento e, portanto, esses sintomas são bastante comuns.

Ao calcularmos o coeficiente alfa de Cronbach do EORTC-QLQ-C30 geral, encontramos alpha $=0,90$, demonstrando confiabilidade no uso do instrumento para esta população.

O Quadro 5 demonstra as médias entre as escalas de Flanagan e EORTC QLQ-C30. Foram relacionados 4 domínios das duas escalas: função física de EORTC equivalente ao bem estar físico e material em Flanagan, função social com relações com outras pessoas, desempenho de pessoal com atividades sociais comunitárias e cívicas, função cognitiva com desenvolvimento pessoal e realizações. 


\begin{tabular}{|c|c|c|c|}
\hline \multicolumn{2}{|c|}{ EORTC } & \multicolumn{2}{c|}{ Flanagan } \\
\hline Domínio & Média & Média & Domínio \\
\hline Função Física & 2,71 & 6,6 & $\begin{array}{c}\text { Bem estar físico e } \\
\text { material }\end{array}$ \\
\hline $\begin{array}{c}\text { Desemão Social } \\
\text { Pessoal }\end{array}$ & 3,14 & 18,3 & $\begin{array}{c}\text { Relações com } \\
\text { outras pessoas }\end{array}$ \\
\hline Função Cognitiva & 3,61 & 7,4 & $\begin{array}{c}\text { Atividades Sociais } \\
\text { comunitárias e } \\
\text { Cívicas }\end{array}$ \\
\hline
\end{tabular}

Quadro 5 - Médias do escores entre as escalas dos instrumentos de Avaliação da Qualidade de Vida EORTC QLQ-C30 e Flanagan.

Para correlacionarmos as médias dos escores entre os dois instrumentos, realizamos o teste de correlação de Spearman, com resultado igual a 0,60, indicando correlação significativa entre os domínios dos dois instrumentos.

As médias de EORTC QLQ-C30 nas funções relacionadas, foram baixas, indicando baixa qualidade de vida. As médias dos Domínios da EQVF também foram baixas, indicando também qualidade de vida ruim. Este resultado demonstra adequação da utilização desses dois instrumentos. 
4-RESULTADOS E DISCUSSÃO 


\subsection{Características Sócio-Demográficas, Clínicas e Terapêuticas}

A Tabela 1 demonstra as características sócio-demográficas dos pacientes entrevistados.

Tabela 1 - Estatística descritiva das características sócio-demográficas da amostra estudada. Aracaju, 2006.

\begin{tabular}{|c|c|c|}
\hline Características & $\mathrm{N}$ & $\%$ \\
\hline \multicolumn{3}{|l|}{ Sexo } \\
\hline Feminino & 09 & 50 \\
\hline Masculino & 09 & 50 \\
\hline \multicolumn{3}{|l|}{ Idade } \\
\hline$<60$ anos & 14 & 77,8 \\
\hline$=$ ou $>60$ anos & 04 & 22,2 \\
\hline \multicolumn{3}{|l|}{ Estado civil } \\
\hline Viúvo (a) & 03 & 16,7 \\
\hline Casado (a) & 07 & 38,9 \\
\hline Separado (a) & 08 & 44,4 \\
\hline \multicolumn{3}{|l|}{ Escolaridade } \\
\hline Analfabeto (a) & 04 & 22,2 \\
\hline Ensino Fundamental Completo & 02 & 11,1 \\
\hline Ensino Fundamental incompleto & 04 & 22,2 \\
\hline Ensino Médio Completo & 05 & 27,8 \\
\hline Ensino Superior incompleto & 01 & 11,1 \\
\hline Ensino Superior Completo & 02 & 5,6 \\
\hline \multicolumn{3}{|l|}{ Procedência } \\
\hline Área urbana & 13 & 72,2 \\
\hline Área rural & 05 & 27,8 \\
\hline \multicolumn{3}{|l|}{ Estado de origem } \\
\hline Pernambuco & 01 & 5,6 \\
\hline Rio de Janeiro & 01 & 5,6 \\
\hline Sergipe & 16 & 88,9 \\
\hline
\end{tabular}


Do ponto de vista sócio-demográfico, foram encontrados $50 \%$ de pessoas do sexo feminino, e $50 \%$ do sexo masculino, esse dado não corrobora com os estudos de Ramsey et al, Mente e Silva [57],e Ortiz et al [58] que apontam uma leve predominância do sexo masculino numa proporção de 3:2 entre estomizados. O estudo de Brown e Randle apud Cancer Research UK 2003 [59] mostrou que a cada ano existem 18.000 novos casos de câncer cólon-retal entre homens e pouco mais de 16.000 em mulheres na União Soviética, havendo aproximadamente 13.500 pessoas com estoma a cada ano.

A média de idade dos pacientes entrevistados foi de 51,3 anos, com desviopadrão de 13 anos e mediana de 53 anos. A idade mínima foi de 25 anos e a máxima de 82 anos. Tais resultados são confirmados pela literatura que indica cerca de $70 \%$ dos portadores deste tipo de neoplasia na faixa etária dos 40 aos 70 anos, ou média de 70,4 anos [60]. Ortiz et al [58], também relatam como idade mais freqüente para colostomias entre a sexta e a sétima décadas de vida $(25,6 \%$ dos casos), em decorrência do carcinoma reto-anal, principal causa da confecção de colostomias. A revisão sistemática de Brown e Randle [61] encontrou idade mais acometida entre 60 e 70 anos.

Segundo estudos realizados por Drumond et al [62], a maioria dos trabalhos que avaliaram pacientes jovens com câncer cólon-retal inclui aqueles com idade igual ou inferior a 40 anos. Entretanto, poucas séries têm sido publicadas sobre pacientes ainda mais jovens que desenvolvem esse tipo de neoplasia.

Drumond et al [62], avaliaram um grupo de pacientes com câncer cólon-retal, com idade inferior a 30 anos, no que diz respeito ao diagnóstico, tratamento, aspectos anátomo patológicos e à evolução da doença. Concluíram que estes são usualmente bastante sintomáticos, com doença avançada ao diagnóstico. Sendo 
provável que a baixa incidência de câncer cólon-retal observada nestes pacientes jovens, leve os médicos a firmarem outros diagnósticos a princípio. Isso, associado ao fato do paciente jovem tender a protelar a procura por assistência médica, pode contribuir para que a confirmação diagnóstica ocorra tardiamente, já com doença avançada loco-regionalmente e à distância. Além disso, a maioria desses tumores pode ser histologicamente considerado como de comportamento mais agressivo, 0 que também contribui para que o prognóstico do câncer cólon-retal, em pacientes com idade inferior a 30 anos, tenda a ser pior. Dessa forma ressalta-se a necessidade do profissional da área de saúde estar preparado e atento para a realização do diagnóstico precoce do câncer cólon-retal.

Quanto à situação conjugal da clientela, 38,9\% são casados (as), 44,4\% separados (as) e 16,7\% viúvos (as). Estudos realizados por Michelone [42], apontam $47,1 \%$ de pacientes com companheiros e $52,9 \%$ sem companheiros. Estudos internacionais apontam entre 60 e $95 \%$ de pessoas casadas $(81,86)$ e alguns estudos nacionais com indivíduos estomizados apontam que a maior parte vive com companheiros, com percentuais de 61,9 a $87,5 \%$ [42].

No estudo de Brown e Randle [61], mais da metade dos participantes entrevistados tinham problemas conjugais, relacionados à presença de colostomia.

O apoio emocional e social da família é de suma importância, considerandose que todo ser humano, independente de ser ou não estomizado, tem necessidade de uma figura de ligação, uma base pessoal segura [43].

O câncer não é uma doença individual, mas sim pertencente à família, pois causa impacto nesta. As famílias devem se confrontar e atentar quanto ao significado do câncer para o paciente, para cada membro da família e para a família como um todo [64]. 
Por isso, a presença do estomizado no seio de uma família constitui motivo para reforçar a base de segurança, procurando promover a sua participação nas atividades do dia-a-dia e sociais, de modo que possa crescer e se desenvolver como membro da família que é. Além do mais, a necessidade de estimar os outros e ser amado por eles é muito gratificante para o ego e constitui necessidade psicoemocional fundamental, principalmente para a pessoa ostomizada ) [65].

Quanto à escolaridade, variou do analfabetismo $(22,2 \%)$ ao nível superior completo (5,6\%). O estudo de Michelone [42] encontrou 47,1\% de analfabetismo entre estomizados a $51,6 \%$ entre pacientes sem estoma. Resultados similares foram encontrados em outros estudos nacionais com clientes portadores de estomas intestinais.

Este dado revela o nível de formação da clientela, não apenas características dos serviços públicos, local onde os dados foram coletados, como o próprio perfil da educação do país. Isto ressalta aos profissionais de saúde, a importância de se passar informações claras e objetivas, conforme conhecimento e linguagem de cada cliente, pois sua independência vai depender de esforços cognitivos, além da habilidade para o desenvolvimento do autocuidado. Situar o cliente no seu contexto sociocultural é fundamental para o sucesso no tratamento. Neste contexto, sobressai ainda mais a presença da família como grande participante na recuperação, promoção de saúde e como co-responsável pela adaptação nas atividades sociais [38].

Outro aspecto social importante foi a procedência, verificando-se neste estudo $72,2 \%$ procedentes da área urbana e $27,8 \%$ da área rural; $88,9 \%$ do estado de Sergipe (50\% Aracaju, 50\% interior do estado), 5,6\% de Pernambuco e $5,6 \%$ do Rio de Janeiro. 
Este foi um dado importante, já que pacientes procedentes da área rural e das cidades do interior de Sergipe possuem maiores dificuldades para a compra e/ou aquisição de dispositivos especiais para estomias, acesso às informações e novidades quanto aos materiais utilizados no cuidado da estomia, pessoal capacitado no atendimento a urgências e emergências a estes pacientes específicos.

A Tabela 2 demonstra as características clínicas dos pacientes entrevistados. 
Tabela 2 - Estatística descritiva das variáveis clínicas da amostra estudada. Aracaju, 2006.

\begin{tabular}{lcc}
\hline Características & N & $\%$ \\
\hline Local do Tumor & 05 & 27,8 \\
Cólon & 07 & 38,9 \\
Reto & 06 & 33,3 \\
Cólon-retal & & \\
& & \\
Presença de metástase & 13 & 83,3 \\
Sim & 05 & 16,7 \\
Não & & \\
Tipo de estoma & 13 & 72,2 \\
Colostomia definitiva & 05 & 27,8 \\
Colostomia provisória & & \\
Tempo de ostomia & 14 & 77,8 \\
$<1$ ano & 04 & 22,2 \\
$\geq 1$ ano & & \\
Presença de complicações no & & 44,4 \\
estoma & 08 & 55,5 \\
Sim & 10 & \\
Não & & \\
\hline
\end{tabular}

A Tabela 2 informa que $38,9 \%$ dos entrevistados apresentavam tumor de localização retal, seguida de cólon-retal $33,3 \%$ e cólon $27,8 \%$. Ao se analisar a distribuição proporcional da ocorrência de casos de câncer na população brasileira, observa-se que o câncer do intestino grosso (cólon, reto e ânus), assim como em outros países, encontra-se entre os dez primeiros tipos de câncer mais incidentes. Para o país como um todo, estimativas realizadas a partir dos dados dos Registros de Câncer de Base Populacional (RCBP) mostram que o número de casos novos esperados para o ano 2006, entre homens e mulheres é, respectivamente, 11.390 e 
13.970, que correspondem a taxas brutas de incidência de 10,96 por 100.000 homens e 11,73 por 100.000 mulheres.

Quanto à presença de metástases, $15(83,3 \%)$ pessoas apresentavam e 03 $(16,7 \%)$ não apresentavam. Em estudo realizado por Drumond et al [62], em pacientes com câncer cólon-retal com idade inferior a 30 anos, 50\% dos casos apresentavam linfonodos acometidos e metástases a distância.

Em relação ao tipo de estoma, destacaram-se $13(72,2 \%)$ com colostomia definitiva e $05(27,8 \%)$ com colostomia provisória. Estudo realizado por Sousa [55], sobre Qualidade de vida em clientes estomizados, 100\% apresentaram colostomia definitiva, reforçando a necessidade de orientação do profissional de saúde quanto aos cuidados com o estoma em todos os seus aspectos.

$77,8 \%$ dos pacientes apresentaram menos de um ano de estoma e $22,2 \%$ mais de um ano de estoma. O tempo de estomizado permite uma melhor adaptação à sua nova condição, não significando, portanto, em melhor qualidade de vida.

Em estudo de Souza [55], 50\% tinham entre 1 e 5 anos de estoma, $12 \% 8$ anos e 37\% mais de 10 anos. Alguns clientes com menos de um ano pós-estoma voltaram às suas atividades e até se sentem em melhores condições de saúde do que antes da cirurgia, no entanto, houve clientes com mais de dez anos que ainda não aceitaram o estoma e sentem-se incapacitados.

Schmidt et al apud Ko et al e Kohler et al [66], em pesquisa realizada com pacientes com doenças na coluna espinhal e doenças inflamatórias crônicas da bexiga referem que colostomias em geral não interferem na qualidade de vida, como usualmente assumido em várias literaturas.

Já Renner et al [67] concluíram que devido à presença de técnicas avançadas em cirurgias retais e os efeitos negativos na qualidade de vida, a colostomia 
permanente deve ser abortada em muitos pacientes. Esta conclusão não utilizou instrumento validado. Pesquisadores $\left[68^{*}\right]$ que usaram questionários câncer e tumorespecífico já validados, tiveram resultados diferentes um ano após a cirurgia.

Dentre as complicações do estoma, destacaram-se 10 (55,6\%) sem presença de complicações e $08(44,4 \%)$ com complicações. Dentre as complicações destacam-ser: edema, deiscência, hemorragia, necrose, hérnia periestoma, prolapso, retração, estenose, granulomas e dermatite periestoma. No presente estudo foram encontradas fístula, retração de estoma, necrose, prolapso e dermatite por reação alérgica ao dispositivo. Algumas destas complicações podem ser evitadas através da utilização de materiais de boa qualidade, orientações com clareza sobre o manuseio destes materiais (quanto à troca, retirada, colocação dos dispositivos), aceitação do próprio indivíduo, apoio psicológico, orientações quanto à dieta, higiene e relacionamento interpessoal.

Pode-se inferir com os dados da tabela 2, que a maioria dos entrevistados com metástase, também apresentavam colostomia definitiva, com menos de um ano de estoma, indícios de que a neoplasia foi diagnosticada em fase avançada da doença, tal fato é esperado entre a população com baixo nível de escolaridade e procedentes da área rural, pois possuem difícil acesso à informação e a um centro de oncologia especializado. Quando o câncer cólon-retal é descoberto em fase avançada, as chances de se optar por uma cirurgia mais invasiva é muito maior do que aquelas descobertas mais precocemente, ocasionando portanto mais efeitos colaterais, interferindo na qualidade de vida.

Schmidt et al apud Grumann et al [69], concluíram que pacientes submetidos à cirurgia de ressecção abdomino-perineal (RAP) não tiveram qualidade de vida pior do que aqueles submetidos à ressecção anterior (RA). Ao contrário, estes 
observaram que pacientes que fizeram ressecção anterior baixa apresentaram níveis de qualidade de vida piores do que aqueles submetidos à ressecção abominoperineal. A qualidade de vida foi prejudicada devido à presença de problemas como incontinência para aqueles submetidos à RA e imagem corporal prejudicada devido à presença de colostomia para pacientes submetidos à RAP.

\subsection{Resultados dos Instrumentos de Avaliação da Qualidade de Vida.}

Os escores médios obtidos nos cinco domínios da Escala de Qualidade de Vida de Flanagan são apresentados na Tabela 3.

Tabela 3: Média e Desvio-padrão dos domínios da Escala de Qualidade de Vida de Flanagan (EQVF) dos pacientes entrevistados.

\begin{tabular}{lccc}
\hline \multicolumn{1}{c}{ Itens da Escala } & Range & Média & Desvio Padrão \\
\hline Bem estar físico e material & $2-12$ & 6,6 & 0,842 \\
\hline Relações com outras pessoas & $4-24$ & 18,3 & 0,790 \\
\hline Atividades Sociais comunitárias e Cívicas & $2-12$ & 7,4 & 0,844 \\
\hline Desenvolvimento Pessoal e realização & $4-24$ & 13,2 & 1,124 \\
\hline Recreação & $3-18$ & 6,8 & 1,261 \\
\hline EQVF Geral & $6-90$ & 52,3 & 1,400 \\
\hline
\end{tabular}

Foram encontradas médias de 6,6 para o domínio bem estar físico e material, 18,3 para o domínio relações com outras pessoas, 7,4 para atividades sociais comunitárias e cívicas, 13,2 para desenvolvimento pessoal e realização, 6,8 para recreação e 52,3 para EQVF Geral.

As médias encontradas indicam qualidade de vida geral regular, a menor média foi o domínio recreação e a maior foi das relações com outras pessoas. 
Infere-se portanto, a importância da família na continuidade do tratamento do paciente e da manutenção de uma rotina próxima a que desenvolvia antes, tanto em atividades domésticas quanto sociais.

Apesar das evidências negativas da presença da estoma, a presença da família e amigos é um sustentáculo para a manutenção da qualidade de vida. A maioria das médias apresentam resultados regular ou ruim, entretanto o relacionamento com outras pessoas apresenta uma média alta.

O estudo de Souza [55], que avaliou a qualidade de vida de pacientes estomizados, demonstrou que a maioria se classificou em regular e ruim em relação ao conforto físico e material. Relação interpessoal entre bom e ótimo, participação em atividades sociais, comunitárias e cívicas entre regular e ruim, desenvolvimento pessoal e realização entre bom e ótimo, recreação entre bom e muito bom.

Ao compararmos os dois estudos, encontramos convergência apenas no domínio relação interpessoal, onde a média variou entre bom e ótimo. Mais uma vez, atribuímos estes dados à caracterização da amostra estudada, ou seja, com baixo nível de escolaridade, procedentes da zona rural, ausência de companheiro (a), além dos aspectos clínicos, como presença de metástases e complicações do estoma.

A recreação foi bastante prejudicada devido à presença de imagem corporal alterada, onde o indivíduo sente vergonha em ter a uma parte do intestino "exposta", se afastam da sociedade por sentirem-se "estigmatizados" frente a algumas pessoas, preferindo manter-se em silêncio acerca da ostomia.

A imagem corporal, segundo Shilder [70], "é a representação do corpo na nossa mente, ou modo pelo qual o corpo se apresenta para nós". A aceitação do seu corpo após o estoma é o primeiro passo para o processo de adaptação e 
reintegração à vida normal. Ressalta-se aqui que de sua própria aceitação depende a reação de outros.

A tabela 4 demonstra a média e desvio-padrão das escalas do instrumento de qualidade de vida EORTC QLQ-C30 dos pacientes tratados de câncer cólon-retal 
Tabela 4 - Média e desvio-padrão das escalas do instrumento de qualidade de vida EORTC QLQ-C30 dos pacientes tratados de câncer cólon-retal.

\begin{tabular}{|c|c|c|}
\hline Itens da Escala & Média & $\begin{array}{l}\text { Desvio } \\
\text { Padrão }\end{array}$ \\
\hline Função física & 46,29 & 29,14 \\
\hline Desempenho de papel & 12,96 & 28,32 \\
\hline Função emocional & 55,09 & 28,45 \\
\hline Função cognitiva & 35,18 & 32,28 \\
\hline Função social & 28,70 & 28,47 \\
\hline Dor & 68,51 & 30,56 \\
\hline Fadiga & 20,19 & 28,84 \\
\hline Náuseas e vômitos & 62,96 & 22,54 \\
\hline Dispnéia & 22,22 & 32,34 \\
\hline Insônia & 51,85 & 39,97 \\
\hline Perda de apetite & 51,86 & 38,30 \\
\hline Constipação & 25,92 & 40,51 \\
\hline Diarréia & 31,48 & 37,00 \\
\hline Dificuldades financeiras & 72,23 & 32,83 \\
\hline Estado geral de saúde / QV & 35,64 & 12,39 \\
\hline
\end{tabular}

As médias encontradas foram: função física 46,29; desempenho de papel 12,96; função emocional 55,09; função cognitiva 35,18 ; função social 28,70 ; dor 68,51; fadiga 20,19; náusea e vômitos 62,96 ; dispnéia 22,22; insônia 51,85 ; perda de apetite 51,86; constipação 25,92; diarréia 31,48; dificuldades financeiras 72,23 e estado geral de saúde 35,64.

Segundo EORTC QLQ-C30 a qualidade de vida geral foi considerada ruim. As baixas médias do estado geral de saúde e da qualidade de vida são explicadas pelo fato da média de sintomas ser alta, e demais funções serem baixas, indicando qualidade de vida ruim. Relacionamos também estes resultados com dados clínicos, como a presença de metástases, e complicações do estoma, além de nível sócioeconômico, escolaridade, que compõem esta amostra.

Os sintomas dor, náusea e vômito, insônia e perda de apetite neste estudo, apresentaram médias altas, indicando a presença dos mesmos. No estudo de 
Santos [54] as médias dos sintomas foram inferiores às observadas neste estudo, indicando melhor qualidade de vida. Justifica-se tal fato pelas características clínicas da amostra estudada, ou seja, presença de metástases, diagnóstico tardio e presença de complicações.

Em estudo de Kerr et al [51], que examinaram o efeito da comunicação abordada pelos profissionais de saúde na qualidade de vida de pacientes com câncer retal, através do instrumento EORTC QLQ-C30, encontraram pior qualidade de vida particularmente associado a problemas de comunicação entre pacientes homens e jovens, pois estes não estavam satisfeitos com as explicações recebidas dos profissionais de saúde sobre o tratamento. Estes pacientes experenciaram insônia, piora da imagem corporal, piora financeira e perspectivas piores de futuro.

\subsection{Relação entre as variáveis sócio-demográficas e clínicas e a qualidade de} vida.

Na tabela 4 estão descritas as médias, desvio-padrão e testes de significância estatística da escala de Flanagan de acordo com as variáveis sócio-demográficas e clínicas. Para o teste de significância estatística, foi realizado teste não paramétrico de Kolmogorov-Smirnov, porém, foram encontrados dados de distribuição normal, por isso optou-se pela aplicação de testes paramétricos: t-student e Análise de Variância (ANOVA), sendo aqui apresentados apenas os valores que foram estatisticamente significantes. 
Tabela 4 - Média, Desvio-padrão e Significância estatística da EQVF de acordo com as variáveis sócio-demográficas e clínicas.

\begin{tabular}{|c|c|c|c|c|c|}
\hline Escala & $\begin{array}{l}\text { Variáveis sócio- } \\
\text { demográficas e } \\
\text { clínicas }\end{array}$ & Variável & Média & $\begin{array}{l}\text { Desvio- } \\
\text { padrão }\end{array}$ & $\begin{array}{c}\mathrm{P} \\
\text { value }\end{array}$ \\
\hline \multirow{5}{*}{$\begin{array}{l}\text { Relações com outras } \\
\text { pessoas }\end{array}$} & \multirow[t]{2}{*}{ Sexo } & Feminino & 4,9444 & ,7784 & \multirow[t]{2}{*}{0,049} \\
\hline & & Masculino & 4,2222 & ,6548 & \\
\hline & \multirow[t]{3}{*}{ Estado de origem } & Pernambuco & 2,75 & - & \multirow[t]{2}{*}{0,045} \\
\hline & & $\begin{array}{l}\text { Rio de } \\
\text { Janeiro }\end{array}$ & 4,5 & - & \\
\hline & & Sergipe & 4,7 & 0,6845 & \\
\hline \multirow[t]{2}{*}{ Atividades Sociais } & \multirow[t]{4}{*}{ Tempo de estoma } & $<1$ ano & 3,92 & 0,7559 & \multirow[t]{2}{*}{0,049} \\
\hline & & $>=1$ ano & 3 & 0,8165 & \\
\hline \multirow{2}{*}{$\begin{array}{l}\text { Desenvolvimento } \\
\text { pessoal e realização }\end{array}$} & & $<1$ ano & 3,57 & 1,08 & \multirow[t]{2}{*}{0,033} \\
\hline & & $>=1$ ano & 2,25 & 0,5 & \\
\hline
\end{tabular}

Foram estatisticamente significativas apenas as escalas: relações com outras pessoas, atividades sociais e desenvolvimento pessoal e realização. Relações com outras pessoas segundo as variáveis sexo $(p=0,049)$ e estado de origem $(p=$ 0,045). Atividades sociais e desenvolvimento pessoal e realização segundo a variável tempo de estoma ( $p=0,049$ e 0,033 respectivamente).

Os pacientes do sexo feminino procedentes do estado de Sergipe apresentaram média superior à dos pacientes do sexo masculino, procedentes dos outros estados, relacionamos este fato à cultura da amostra estudada, onde as mulheres têm menos preconceito ao abordarem assuntos relacionados a sua doença.

No estudo de Michelone [42], que utilizou o WHOQOL-bref, as mulheres apresentaram escores médios mais altos nos domínios psicológicos, relações sociais e meio ambiente quando comparado ao grupo de homens. 
Em relação à procedência e relações com outras pessoas, verifica-se média maior entre aqueles de Sergipe, já que estes apresentam como traço cultural, a interatividade entre as pessoas, comparados com outros estados como Rio de Janeiro e Pernambuco, que são regiões com características metropolitanas. Situar o cliente no seu contexto sociocultural torna-se fundamental para o sucesso no tratamento e recuperação.

Segundo o tempo de estoma, a maior média está entre os clientes com menos de um ano de estoma, relacionando-se com a participação em atividades comunitárias e cívicas, além do desenvolvimento pessoal e realização, que trata de atividades profissionais e domésticas, com diferença estatisticamente significante.

Percebe-se que os pacientes com menos de um ano de estoma apresentam maior atividade social, desenvolvimento pessoal e realização do que aqueles com mais de um ano de estoma, pois a maioria dos pacientes foram submetidos à confecção da estoma tardiamente, já com metástases e para fins paliativos. Estes dados corroboram com os da pesquisa de Michelone [42], que encontrou no domínio relações sociais, escores mais elevados entre os indivíduos operados há menos de um ano, porém, sem diferença estatisticamente significante.

Martisson [71], Trentini et al [72] e Santos [73] relacionam como uma das dificuldades de retorno ao trabalho e como causas do isolamento social do estomizado, a etiologia do estoma.

A tabela 5 descreve as médias, desvio-padrão e os testes de significância estatística das escalas do EORTC QLQ-C30 de acordo com as variáveis sóciodemográficas. Para o teste de significância estatística, também foi realizado teste não paramétrico de Kolmogorov-Smirnov, porém, foram encontrados dados de 
distribuição normal, por isso optou-se pela aplicação de testes paramétricos: $t$ student e Análise de Variância (ANOVA), sendo aqui apresentados apenas os valores que foram estatisticamente significantes. 
Tabela 5 - Média, Desvio-padrão e Significância estatística do EORTC QLQ-C30 de acordo com as variáveis sócio-demográficas.

\begin{tabular}{|c|c|c|c|c|c|}
\hline Escala & $\begin{array}{l}\text { Variáveis sócio- } \\
\text { demográficas e clínicas }\end{array}$ & Variável & Média & $\begin{array}{l}\text { Desvio } \\
\text { padrão }\end{array}$ & $\begin{array}{c}\mathrm{P} \\
\text { value }\end{array}$ \\
\hline \multirow[t]{3}{*}{ Função física } & \multirow[t]{3}{*}{ Estado civil } & Viúvo & 6,66 & 11,54 & \multirow[t]{3}{*}{0,012} \\
\hline & & Casado & 61,90 & 29,24 & \\
\hline & & Separado & 47,5 & 19,33 & \\
\hline \multirow[t]{3}{*}{ Dor } & \multirow[t]{3}{*}{ Estado Civil } & Viúvo & 94,4 & 9,64 & \multirow[t]{3}{*}{0,013} \\
\hline & & Casado & 52,4 & 20,26 & \\
\hline & & Separado & 60,41 & 17,67 & \\
\hline \multirow{4}{*}{$\begin{array}{l}\text { Estado geral de } \\
\text { Saúde }\end{array}$} & \multirow[t]{2}{*}{ Sexo } & Masculino & 41,66 & 13,17 & \multirow[t]{2}{*}{0,35} \\
\hline & & Feminino & 29,62 & 8,44 & \\
\hline & \multirow[t]{2}{*}{ Complicações } & Sim & 44,79 & 8,83 & \multirow[t]{2}{*}{0,012} \\
\hline & & Não & 28,33 & 9,78 & \\
\hline \multirow[t]{4}{*}{$\begin{array}{l}\text { Dificuldades } \\
\text { financeiras }\end{array}$} & \multirow[t]{2}{*}{ Procedência } & $\begin{array}{l}\text { Área } \\
\text { Urbana }\end{array}$ & 64,11 & 34,59 & \multirow[t]{2}{*}{0,24} \\
\hline & & Área rural & 93,34 & 14,89 & \\
\hline & \multirow[t]{2}{*}{ Complicações } & Sim & 91,67 & 15,41 & \multirow[t]{2}{*}{0,015} \\
\hline & & Não & 56,68 & 35,31 & \\
\hline \multirow[t]{2}{*}{ Dispnéia } & \multirow[t]{2}{*}{ Metástase } & Sim & 26,66 & 33,81 & \multirow[t]{2}{*}{0,09} \\
\hline & & Não & 0 & 0 & \\
\hline \multirow[t]{2}{*}{ Fadiga } & \multirow{6}{*}{ Tempo de estoma } & $<1$ ano & 61,9 & 31,35 & \multirow[t]{2}{*}{0,009} \\
\hline & & $>=1$ ano & 91,67 & 10,62 & \\
\hline \multirow{2}{*}{$\begin{array}{l}\text { Náusea e } \\
\text { Vômitos } \\
\end{array}$} & & $<1$ ano & 12,39 & 20,9 & \multirow[t]{2}{*}{0,027} \\
\hline & & $>=1$ ano & 47,49 & 39,2 & \\
\hline \multirow[t]{2}{*}{ Constipação } & & $<1$ ano & 14,28 & 31,25 & \multirow[t]{2}{*}{0,017} \\
\hline & & $>=1$ ano & 66,67 & 47,14 & \\
\hline \multirow{2}{*}{$\begin{array}{l}\text { Função } \\
\text { emocional }\end{array}$} & \multirow[t]{2}{*}{ Complicações } & Sim & 72,91 & 23,03 & \multirow[t]{2}{*}{0,012} \\
\hline & & Não & 40,83 & 24,67 & \\
\hline
\end{tabular}

Foram estatisticamente significativas as escalas: função física, dor, estado geral de saúde, dificuldades financeiras, dispnéia, fadiga, náusea e vômito, constipação e função emocional. A função física teve como variável estatisticamente significante o estado civil, com $p=0,012$, com maior média entre pessoas casadas, assim como a escala dor, com $p=0,013$, porém com maior média entre as pessoas viúvas.

A função física entre as pessoas casadas foi maior, indicando que as pessoas casadas apresentam menos dificuldades para desempenhar atividades físicas no 
domicilio ou fora dele, sugerindo a importância da presença da família. Estes dados corroboram com os do estudo de Michelone [42], onde o grupo de estomizados obteve escores mais altos no domínio físico entre aqueles com companheiros, apesar de não ter encontrado diferença estatisticamente significante.

No sintoma dor, a presença desta, foi maior entre o grupo de pessoas viúvas e separadas, em relação aos casados. Inferimos neste resultado, novamente a importância da presença da família e/ou amigos para amenizar os sintomas, neste caso, a presença da dor.

Na escala estado geral de saúde, foram estatisticamente significativos o sexo e complicações do estoma, com médias superiores entre aqueles do sexo masculino e com presença de complicações. Significando que os homens classificaram sua qualidade de vida e saúde geral melhores do que as mulheres, encontramos também a influencia da presença de complicações no domínio Estado geral de saúde e Qualidade de vida.

$\mathrm{Na}$ escala dificuldades financeiras, a procedência e as complicações do estoma foram estatisticamente significantes, $p=0,24$ e $p=0,015$ respectivamente. Com maiores médias entre aqueles da área rural e com presença de complicações do estoma. Demonstrando maiores dificuldades financeiras dentre as pessoas procedentes da área rural e com complicações no estoma, já que as dificuldades dos moradores da área rural são maiores, no que se refere ao acesso ao tratamento de modo geral.

No sintoma dispnéia, a variável estatisticamente significante foi a presença ou não de metástase, com $p=0,09$, com maior média entre aqueles com metástases. Já os sintomas fadiga, náusea e vômitos e constipação, apresentou como única variável estatisticamente significante o tempo de estoma, $p=0,009,0,027$ e 0,017 
respectivamente. Mostrando maiores médias entre aqueles com tempo de estoma maior ou igual a um ano em todos estes sintomas, podendo-se inferir que o avanço da doença e a presença de metástase foram fatores determinantes no aumento dos sintomas.

$\mathrm{Na}$ escala função emocional, a variável complicações do estoma foi estatisticamente significante, $p=0,012$, havendo maior média entre aqueles com presença de complicações do estoma. Este resultado demonstra a influência da presença do estoma nas condições emocionais.

\subsection{Regressão Linear Múltipla}

A tabela 6 demonstra a proporção da variação explicada $\left(R^{2}\right)$ da $E Q V F$, onde foi relatado apenas a escala relações com outras pessoas, por ser a única estatisticamente significante. Algumas variáveis independentes foram mantidas no modelo, apesar de não apresentar significância estatística, pois contribuíram para o aumento da explicação da variação.

A escala Relações com outras pessoas foi influenciada pelas variáveis: sexo, tempo de estoma e estado de origem. Este resultado confirma os dados já discutidos, ressaltando a importância da influência cultural e a gravidade da doença, nas relações sociais. 
Tabela 6 - Resultados da Regressão Linear Múltipla para EQVF, escala relações com outras pessoas.

\begin{tabular}{|c|c|c|c|c|c|}
\hline ESCALA & $\mathbf{R}^{2}$ & $\begin{array}{l}\text { p (teste } \\
\text { F) }\end{array}$ & VARIAVEL & COEFICIENTE & $\mathbf{P}$ \\
\hline \multirow{3}{*}{$\begin{array}{l}\text { Relações com } \\
\text { outras pessoas }\end{array}$} & \multirow[t]{3}{*}{0,467} & \multirow[t]{3}{*}{0,028} & Sexo & $-0,638$ & 0,053 \\
\hline & & & $\begin{array}{l}\text { Tempo de } \\
\text { estoma }\end{array}$ & $-0,107$ & 0,773 \\
\hline & & & $\begin{array}{l}\text { Estado de } \\
\text { origem }\end{array}$ & 0,755 & 0,026 \\
\hline
\end{tabular}

A tabela 7 demonstra a proporção da variação explicada $\left(R^{2}\right)$ do EORTC QLQ-C30, foram descritas as escalas função emocional, dispnéia, dificuldade financeira e estado Geral de Saúde, que foram significativamente estatísticos. Algumas variáveis independentes foram mantidas no modelo, apesar de não apresentar significância estatística, pois contribuíram para o aumento da explicação da variação. 
Tabela 7 - Resultados da Regressão Linear Múltipla para EORTC QLQ-C30.

\begin{tabular}{|c|c|c|c|c|c|}
\hline ESCALA & $\mathbf{R}^{2}$ & $\begin{array}{l}\text { p (teste } \\
\text { F) }\end{array}$ & VARIAVEL & COEFICIENTE & $\mathbf{P}$ \\
\hline \multirow{6}{*}{$\begin{array}{l}\text { Função } \\
\text { emocional }\end{array}$} & \multirow[t]{6}{*}{0,760} & \multirow[t]{6}{*}{0,006} & Sexo & 3,860 & 0,717 \\
\hline & & & Estado Civil & $-8,654$ & 0,287 \\
\hline & & & Procedência & 28,233 & 0,028 \\
\hline & & & Metástase & 10,535 & 0,523 \\
\hline & & & $\begin{array}{l}\text { Tempo de } \\
\text { estoma }\end{array}$ & $-35,037$ & 0,006 \\
\hline & & & Complicações & $-40,790$ & 0,002 \\
\hline \multirow[t]{6}{*}{ Dispnéia } & \multirow[t]{6}{*}{0,778} & \multirow[t]{6}{*}{0,004} & Sexo & $-50,302$ & 0,001 \\
\hline & & & Estado Civil & $-19,794$ & 0,039 \\
\hline & & & Procedência & 40,601 & 0,007 \\
\hline & & & Metástase & $-36,267$ & 0,062 \\
\hline & & & $\begin{array}{l}\text { Tempo de } \\
\text { estoma }\end{array}$ & $-2,414$ & 0,836 \\
\hline & & & Complicações & 34,106 & 0,009 \\
\hline \multirow{6}{*}{$\begin{array}{l}\text { Dificuldade } \\
\text { Financeira }\end{array}$} & \multirow[t]{6}{*}{0,649} & \multirow[t]{6}{*}{0,038} & Sexo & $-8,377$ & 0,574 \\
\hline & & & Estado Civil & $-19,035$ & 0,105 \\
\hline & & & Procedência & 24,152 & 0,148 \\
\hline & & & Metástase & 38,195 & 0,114 \\
\hline & & & $\begin{array}{l}\text { Tempo de } \\
\text { estoma }\end{array}$ & 9,851 & 0,512 \\
\hline & & & Complicações & $-48,615$ & 0,005 \\
\hline \multirow{6}{*}{$\begin{array}{l}\text { Estado geral } \\
\text { de Saúde }\end{array}$} & \multirow[t]{6}{*}{0,657} & \multirow[t]{6}{*}{0,035} & Sexo & $-5,153$ & 0,361 \\
\hline & & & Estado Civil & 4,348 & 0,303 \\
\hline & & & Procedência & $-2,748$ & 0,645 \\
\hline & & & Metástase & $-7,397$ & 0,393 \\
\hline & & & $\begin{array}{l}\text { Tempo de } \\
\text { estoma }\end{array}$ & $-2,121$ & 0,704 \\
\hline & & & Complicações & $-12,287$ & 0,035 \\
\hline
\end{tabular}

A escalas função emocional, dispnéia, dificuldade financeira e estado geral de saúde tiveram influência das variáveis sexo, estado civil, estado de procedência, metástase, tempo de estoma e complicações.

Portanto, a Regressão Linear Múltipla confirma os dados dos testes paramétricos (t-test e ANOVA), discutidos ao longo do trabalho tanto para Flanagan, quanto para EORTC QLQ-C30. 
Esta pesquisa possibilitou as seguintes conclusões:

- Com relação à confiabilidade do instrumento para a amostra encontramos:

O coeficiente alfa de Cronbach excedeu 0,70 em todas as escalas da EQVF, exceto o Domínio 2, sobre Relacionamento com outras pessoas.

No questionário EORTC QLQ-C30 do total de nove escalas, cinco apresentaram Coeficiente Alfa de Crobach acima de 0,70: Função física, desempenho de pessoal, função emocional, fadiga e náusea e vômito. As escalas função social, função cognitiva, dor e estado geral de saúde apresentaram coeficiente menor que 0,70 . O resultado geral do EORTC QLQ-C30 foi de alpha = 0,90, indicando consistência interna do instrumento.

Para a correlação entre as médias dos escores dos dois instrumentos, foi realizado o teste de correlação de Spearman, com resultado igual a 0,60, demonstrando correlação significativa entre os domínios dos dois instrumentos: Flanagan e EORTC QLQ-C30, possibilitando a adequação do uso destes dois instrumentos.

- Com relação às características sócio-demográficas e clinicas da amostra foram evidenciados:

Quanto ao sexo, $50 \%$ são do sexo feminino, e $50 \%$ do masculino. A média de idade foi de 51,3 anos. A idade mínima foi de 25 anos e a idade máxima de 82 anos. Quanto à situação conjugal, $38,9 \%$ são casados (as), 44,4\% separados (as) e 16,7\% viúvos (as). Quanto à escolaridade, variou do analfabetismo $(22,2 \%)$ ao nível superior completo (5,6\%). Quanto à procedência, 72,2\% área urbana e 27,8\% área 
rural; $88,9 \%$ do estado de Sergipe (50\% Aracaju, 50\% interior do estado), 5,6\% de Pernambuco e $5,6 \%$ do Rio de Janeiro.

Quanto à localização do tumor, 38,9\% tumor de reto, seguida de cólon-retal $33,3 \%$ e cólon 27,8\%. Quanto à presença de metástases, 15 (83,3\%) pessoas apresentavam e $03(16,7 \%)$ não apresentavam. Em relação ao tipo de estoma, destacaram-se $13(72,2 \%)$ com colostomia definitiva e $05(27,8 \%)$ com colostomia provisória. $77,8 \%$ dos pacientes apresentaram menos de um ano de estoma e $22,2 \%$ mais de um ano de estoma. Dentre as complicações da estomia, destacaram-se 10 (55,6\%) sem presença de complicações e $08(44,4 \%)$ com complicações.

\section{- Com relação à análise de qualidade de vida da amostra:}

Para EQVF foram encontrados médias de 6,6 (DP=0,842) para o domínio bem estar físico e material, 18,3 $(\mathrm{DP}=0,79)$ para o domínio relações com outras pessoas, 7,4 (0,844) para Atividades Sociais Comunitárias e Cívicas, 13,2 $(\mathrm{DP}=1,124)$ para desenvolvimento Pessoal e realização, 6,8 $(\mathrm{DP}=1,261)$ para Recreação e 52,3 (DP=1,40) para EQVF Geral.

Para EORTC QLQ-C30, as médias encontradas foram: função física 46,29 $(D P=29,14)$; desempenho de papel 12,96 ( $D P=28,32)$; função emocional 5,09 (DP=28,45); função cognitiva 35,18 ( $\mathrm{DP}=32,28)$; função social 28,70 (DP=28,47); dor 68,51 ( $\mathrm{DP}=30,56)$; fadiga 20,19 ( $\mathrm{DP}=28,84)$; náusea e vômitos 62,96 ( $\mathrm{DP}=22,54$ ); dispnéia 22,22 ( $\mathrm{DP}=32,34)$; insônia 51,85 ( $\mathrm{DP}=39,97)$; perda de apetite 51,86 ( $\mathrm{DP}=38,30)$; constipação 25,92 ( $\mathrm{DP}=40,51)$; diarréia 31,48 ( $\mathrm{DP}=37)$; dificuldades financeiras 72,23 (DP=32,83); estado geral de saúde 35,64 (DP=12,39). 
Foram estatisticamente significativas apenas as escalas: relações com outras pessoas, atividades sociais e desenvolvimento pessoal e realização . Relações com outras pessoas segundo as variáveis sexo $(p=0,049)$ e procedência $(p=0,045)$. Atividades sociais e Desenvolvimento pessoal e realização segundo a variável tempo de estoma ( $p=0,049$ e 0,033 respectivamente).

Os pacientes do sexo feminino procedentes do Estado de Sergipe apresentaram média superior à dos pacientes do sexo masculino, procedentes dos outros estados.

Em relação à procedência e relações com outras pessoas, verifica-se média maior entre aqueles de Sergipe do que aqueles de outros estados como Rio de Janeiro e Pernambuco.

Segundo o tempo de estoma, a maior média está entre os clientes com menos de um ano de estoma, com diferença estatisticamente significante. Pacientes com menos de um ano de estoma, apresentam maior atividade social, desenvolvimento pessoal e realização do que aqueles com mais de um ano de estoma.

Foram estatisticamente significativas as escalas: função física, dor, estado geral de saúde, dificuldades financeiras, dispnéia, fadiga, náusea e vômito, constipação e função emocional. A função física teve como variável estatisticamente significante o estado civil, com $p=0,012$, com maior média entre pessoas casadas, assim como a escala dor, com $p=0,013$, porém com maior média entre as pessoas viúvas.

A função física entre as pessoas casadas foi maior. No sintoma dor, a presença desta, foi maior entre o grupo de pessoas viúvas e separadas, em relação 
aos casados. Na escala estado geral de saúde, foram estatisticamente significativos o sexo e complicações do estoma, com médias superiores entre aqueles do sexo masculino e com presença de complicações. Na escala Dificuldades financeiras, a procedência e as complicações do estoma foram estatisticamente significantes, $p=$ 0,24 e $p=0,015$ respectivamente. Com maiores médias entre aqueles da área rural e com presença de complicações do estoma. No sintoma dispnéia, a variável estatisticamente significante foi a presença ou não de metástase, com $p=0,09$, com maior média entre aqueles com metástases. Já os sintomas fadiga, náusea e vômitos e constipação, apresentou como única variável estatisticamente significante o tempo de estoma, $p=0,009,0,027$ e 0,017 respectivamente. Na escala função emocional, a variável complicações do estoma foi estatisticamente significante, $p=$ 0,012, havendo maior média entre aqueles com presença de complicações do estoma.

A escala Relações com outras pessoas foi influenciada pelas variáveis: sexo, tempo de estoma e estado de origem, conforme cálculo de Regressão Linear Múltipla. As escalas Função emocional, Dispnéia, Dificuldade financeira e Estado Geral de Saúde tiveram influência das variáveis sexo, estado civil, estado de procedência, metástase, tempo de estoma e complicações. 
6-CONSIDERAÇÕES FINAIS 
Os estudos acerca da qualidade de vida levam-nos a compreender a individualidade do cliente e ajudá-los a tomar a melhor decisão relacionada às opções acerca de seu tratamento. Buscar o melhor e mais adequado instrumento para se avaliar a qualidade de vida do paciente com estoma intestinal secundário ao câncer cólon-retal não é uma tarefa fácil, já que em vários instrumentos são detectados restrições para o estomizado. A escala de qualidade de vida de Flanagan apontou dados gerais acerca da qualidade de vida e o EORTC QLQ-C30 focalizou dados específicos.

A qualidade de vida dos estomizados intestinais depende de vários fatores detectados na pesquisa: da correta localização do estoma; de uma adaptação psicológica adequada à nova mudança; da existência de um acompanhamento profissional especializado durante todas as fases do internamento (estar disponível para ouvir, ensinar, ajudar); mas também de um apoio especializado no período pós alta hospitalar, onde o estomizado, e/ou seus familiares possam recorrer sempre que Ihe surjam dúvidas ou problemas relacionados com a sua patologia. Esse apoio especializado deve ser oferecido por uma equipe de saúde capacitada para tal, já que cada indivíduo reage de uma forma diferenciada.

Durante este estudo vários foram os problemas detectados no acompanhamento destes pacientes, onde encontramos serviços desestruturados, onde o cliente sente-se inseguro quanto aos procedimentos de instalação e retirada do dispositivo e conteúdo do mesmo, profissionais despreparados, tanto pela sobrecarga de trabalho, quanto pelo próprio despreparo do profissional, falta de acompanhamento pelo enfermeiro, no pós-operatório, na colocação de bolsa de estoma intestinal, dentre outros. 
Portanto, esta nova condição "ser estomizado" e com câncer cólon-retal, coloca, para nós, profissionais de saúde, o objetivo de buscar conseguir um nível de satisfação e/ou adaptação à vida de cada paciente, que o faça se sentir "saudável", sempre com abordagem familiar, social e profissional. 
7-REFERÊNCIAS BIBLIOGRÁFICAS 
[1].BRASIL. Ministério da Saúde. Secretaria de Assistência à Saúde. Instituto Nacional de Câncer. Falando sobre câncer do intestino / Instituto Nacional de Câncer, Sociedade Brasileira de Coloproctologia, Colégio Brasileiro de Cirurgiões, Associação Brasileira de Colite Ulcerativa e Doença de Crohn, Colégio Brasileiro de Cirurgia Digestiva, Sociedade Brasileira de Endoscopia Digestiva, Sociedade Brasileira de Cancerologia, Sociedade Brasileira de Oncologia Clínica. Rio de Janeiro: INCA, 2003. 36p.

[2]. Brasil. Ministério da Saúde. Secretaria de Atenção à Saúde. Instituto Nacional de Câncer. Coordenação de Prevenção e Vigilância. Estimativa 2005: Incidência de Câncer no Brasil. Rio de Janeiro: INCA, 2004. 94p. il.

[3]. Hawk, ET; Levin, B. Colorectal cancer prevention. Journal of Clinical Oncology, 2005, jan 10, 23(2): 378-91.

[4]. Brasil. Ministério da Saúde. Secretaria Nacional de Assistência à Saúde. Instituto Nacional de Câncer. Estimativas da incidência e mortalidade por câncer no Brasil. Rio de Janeiro: INCA, 2006.

[5].Paramore, J.B.; Wei, J.P.;Yeh, K.A. Colorectal cancer in patients under forty: presentation and outcome. Am Surg 1998; 64: 563-7. 
[6]. Minardi, A.J.Jr.; Sitting, K.M.; Zibari, G.B., McDonald, J.C. Colorectal câncer in the Young patient. Am Surg 1998; 64: 849-53.

[7]. Adachi M, Ryan P, Collopy B, et al: Adenoma-carcinoma sequence of the large bowel. Aust N Z J Surg, 1991, 61:409-14.

[8]. Colditz, G. et al. Harvard Report on Cancer Prevention. Volume 1. Causes of Human Cancer. Cancer Causes Control 7:1-59 - 1996. FUCHS, C. et al. A prospective history and the risk of colorectal cancer. N. Engl. J. Med., 1994, 331: 1669-74.

[9]. Brasil. Ministério da Saúde. Secretaria Nacional de Assistência à Saúde. Instituto Nacional de Câncer. Disponível em: http://www.inca.gov.br Acesso em 21 de junho de 2004.

[10]. American Gastroenterological Association. Colorectal cancer screening and surveillance: Clinical guidelines and rationale - Update based on new evidence. Gastroenterolgy 2003;124:544-560. U.S. PREVENTIVE SERVICES TASK FORCE.

[11]. American Joint Committee on Cancer. Manual for staging cancer. Philadelphia, J.B. Lippincott, 1983.

[12]. Cruz, GMG; Ferreira, RMRS; Neves, PM. Amputação abdominoperineal: uma cirurgia for a de moda. Rev. brás. Coloproct., 2004, 24 (2):103-18. 
[13]. Habr-Gama, A. Colorectal cancer: the importance of prevention. Arq. Gastroenterol., Jan./Mar. 2005, 42(1): 2-3.

[14]. Vukovich, V.C.; Grubb, R.D. Care of the ostomy patient. 2a ed., Saint Louis, Mosby, 1977. cap.2, p.5-37: Functions of the ostomy nurse.

[15]. Anderson, F.J. History of enterostomal therapy. In: Broadwell, D.C.; Jackson, B.S. Principles of ostomy care. Saint Louis, Mosby, 1982. cap. 3: 14-6.

[16]. Beart, R.W. Prevention and management o frecurrent rectal câncer. World $\mathrm{J}$ Surg 1991:15:589-91.

[17]. Reis Neto, J.A. et al. Radioterapia pré-operatória em câncer do reto baixo: avaliação dos efeitos da irradiação nas células indiferenciadas e sua influência no prognóstico. Rev Bras Colo-proct, 1998; 18(1):11-16.

[18]. Aguilar,PS. et al. Diseases of the colon and rectum. Publisher: Springer New York, November, 1991, 34(11): 959-63.

[19]. Paula, MAB; Santos, VLCG. O significado de ser especialista para o enfermeiro estomaterapêuta. Rev.Latino-Am. Enfermagem, Ribeirão Preto, jul/ago, 2003, 11(4). 
[20]. Santos, V.L.C.G.; Cesaretti, I.U.R. Assistência em estomaterapia: cuidando do ostomizado. In: Santos, V.L.C.de; Kimura, M.. Qualidade de vida e a reabilitação do ostomizado. São Paulo: Editora Atheneu, 2000: 453-75.

[21]. Lima, T.G.S. Curso de estomaterapia: derivações urinárias. Rev Enferm. Atual., maio-jun, 2002: 20-22.

[22]. Brasil. Ministério da Saúde. Secretaria Nacional de Assistência à Saúde. Instituto Nacional de Câncer. Estimativas da incidência e mortalidade por câncer no Brasil. Rio de Janeiro: INCA, 2003.

[23]. Kretschmer, K.P. Estomas intestinais: indicações, métodos operatórios, cuidados e reabilitação. São Paulo: Interamericana, 1992.

[24]. Santos, V.L.C.G.; Kimura, M. Qualidade de vida e a reabilitação do ostomizado. In: Santos, V.L.C.G.; Cesaretti, I.U.R. Assistência em estomaterapia: cuidando do ostomizado. São Paulo: Atheneu; 2001: 453-75.

[25]. Bekkers, M.J.T.M. et al Psycholosocial adaptation to stoma surgery: a review. Journal of Behavioral Medicine, USA, 1995, 18(1).

[26]. Fundação Oncocentro de São Paulo. Manual de Oncologia Clinica. $6^{a}$ edição. São Paulo: Springer - Verlag, 1999. 
[27]. Casciato, DA; Lowitz, BB. Manual de Oncologia Clínica. 2ed. Rio de Janeiro: Medsi, 1991.

[28]. Breckaman, B. Enfermería del estoma. Madrid: Interamericana/McGraw Hill, 1987.

[29]. Boccardo, LM et al. Aspectos da reinserção social do ostomizado. Rev.Esc.Enf.USP, 1995, 29(1): 59-71.

[30]. Zago, MMF; Casagrande, LDR. As necessidades de aprendizagem dos pacientes laringectomizados. Rev.Gaúcha Enf., 1992, Porto Alegre, 13(2): 17-21.

[31]. Sonobe, HM; Barichello, E.; Zago, MMF. A visão do colostomizado sobre o uso da bolsa de colostomia. Revista Brasileira de Cancerologia, 2002, 48(3) Jul/Ago/Set.

[32]. Gemelli, LMG; Zago, MMF. A interpretação do cuidado com o ostomizado na visão do enfermeiro: um estudo de caso. Rev Latino-Americana de Enfermagem, 2002, 10(1).

[33]. Andrade, V. et al. A sexualidade do ostomizado na visão do parceiro (Parte I). Rev Bras Colo-Proct, 1997;17(3): 209-11. 
[34]. Meirelles, CA; Ferraz, CA. Avaliação da qualidade do processo de demarcação do estoma intestinal e das intercorrências tardias em pacientes ostomizados. Rev Latino-Americana de Enfermagem, 2001, 9(5).

[35]. Viscott D. A linguagem dos sentimentos. São Paulo (SP): Sumus; 1982.

[36]. Shilder. Assessment of quality of life in pediatric cancer patients at diagnosis and during therapy. Turkish Journal of Cancer, 2001, 31(4).

[37]. Shipes, E. Psychosocial issue: the person with ostomy. Nurs.Clin.North Am., 1987, 22(2): 291-302.

[38]. Hashimoto, H; Guedes, SL; Pereira, VC. O ostomizado e a qualidade de vida: abordagem fundamentada nas dimensões da qualidade de vida proposta por Flanagan. São Paulo, 1996, 37p. Monografia (Especialização em Estomaterapia), Escola de Enfermagem, Universidade de São Paulo, 1996.

[39]. WHOQOL GROUP. The development of the World Health Organization Quality of Life assessement instrument. In: Quality of life assessment: international perspectives. (edited by Orley j. and Kuyken, W.). Springer Verlag, Heildelberg: p. 41-60, 1994.

[40]. Lentz RA, Costenaro RGS, Gonçalves LHT, Nassar SM. O profissional de enfermagem e a qualidade de vida: uma abordagem fundamentada nas dimensões propostas por Flanagan. Rev Latino-Am Enfermagem 2000; 8(4):7-14. 
[41]. Minayo, MCS. O desafio do conhecimento - pesquisa qualitativa em saúde. $4^{a}$ ed. São Paulo: Hucitec - Abrasco, 1996.

[42]. Michelone, A.deP.C. Qualidade de vida de adultos com câncer colorretal com e sem estoma. 2002. 116p. Dissertação (Mestrado). Escola de Enfermagem de São Paulo, Universidade de São Paulo, São Paulo, 2002.

[43]. Santos, VLCG; Koizumi, MS. Sentimentos e sugestões manifestadas por colostomizados que se auto-irrigam. Rev Esc Enferm USP, 1992; 26:161-72.

[44]. Farquhar, M. Definitions of quality of life: a toxonomy. Journ. of Adv. Nurs., v.22, p. 502-8, 1995.

[45]. Katz, S. The science of quality of life. J.Chron.Dis., v.40, n.6, p.459-63, 1987.

[46]. Svelund, J; Sullivan, M; Sjodin, I, Liedman, B; Lundell, L. Quality of life in cancer prior to gastrectomy. Quality of life research, v.5,p.255-64, 1996.

[47]. Cella, DF; Tulsky, DS. Measuring the quality of life today: methodological aspects. Oncology (Huntingt), 1990; 4(5): 29-38.

[48]. Bowling, A. La medida de la salud: revisión de las escalas de medida de calidad de vida. Barcelona: Masson S.A., 1994. 
[49]. Santos SR, Santos IBC, Fernandes MGM, Henriques ME. Qualidade de vida do idoso na comunidade: aplicação da escala de Flanagan. Rev Latino-am Enfermagem 2002; 10(6):757-64.

[50]. Brabo E. Validação do EORTC QLQ-C30. [mensagem pessoal]. Mensagem recebida por emonteiro@hcancer.org.br em 24 jun. 2001.

[51]. Kerr, J; Engel, J; Raab, AS; Sauer, H; Hölzel. Doctor-patient communication: results of a four-year prospective study in rectal cancer patients. Dis Colon Rectum, 2003, August, 46 (8): 1038-46.

[52]. Nassar SM, Gonçalves LHT. A avaliação de uma medida de qualidade de vida. Texto Contexto Enfermagem 1999; 8(3):99-110.

[53]. Santos, EMM. Câncer colorretal: qualidade de vida em pacientes tratados com intenção curativa. Dissertação(mestrado), Fundação Antonio Prudente. Curso de Pós-graduação em Ciências, Área de concentração: Oncologia. São Paulo, 2003, 88p.

[54]. Norusis MJ. SPSS/PC. Professional statistics. Chicago: SPSS Inc.; 1992.

[55]. Souza, MAS. Qualidade de vida em clientes ostomizados. Texto Contexto Enferm 1999; 8(3):162-82. 
[56]. Sprangers, MAG; Taal, BG; Aaronson, NK; Te Velde, A. Quality of life in colorectal câncer: stoma vs. nonstoma patients. Dis Colon Rectum, 1995; 38:3619.

[57]. Ramsey, SD; Andersen, MR; Etzioni, R, et al. Quality of life on survivors of colorectal carcinoma. Cancer 2000; 88: 1294-303.

[58]. Ortiz, H.; Martirague, J.; Foulkes, B. Indicaciones y cuidados de los estomas. Buenos Aires: Editorial Jims S.A., 1994.

[59]. Cancer Research UK 2003. Disponível em: http://www.cancerbacup.org.uk, acesso em 19 jan. 2005.

[60]. Lupinacci, RM; Campos, FGMC et al. Análise comparativa das características clínicas anátomo-patológicas e sobrevida entre pacientes com câncer cólon-retal abaixo e acima de 40 anos de idade. Rev Bras Coloproct, 2003; 23(3):155-62.

[61]. Brown, H.; Randle, J. Living with a stoma: a review of the literature. Journal of Clinical Nursing; 2005; 14: 74-81.

[62]. Drumond, CA et al. Cancer cólonrretal em pacientes com idade inferior a 30 anos. Revista Brasileira de Coloproctologia, v.23, n.3, jul./set., 2003, p.147-54. 
[63]. Apolone, G; Filiberti, A; Cifani, S; Ruggiata, R; Mosconi, P. Evaluation of the EORTC QLQ-C30 questionnaire: a comparison with the SF-36 Health Survey in a cohort of Italian long-survival cancer patients. Ann Oncol 1998; 9:549-57.

[64]. Mystakidou, $\mathrm{K}$ et al apud Blanchard, GC et al. Patient-family communication with physicians. Cancer and the family, 1996, 369-87.

[65]. Bowlby, L. Formação e rompimento dos laços afetivos. São Paulo, Martins Fonseca, 1982. Cap.6: Autoconfiança e algumas condições que a promovem. P.97-117.

[66]. Ko, CY; Rusin, LC; Schoetz, DJ, et al. Using quality of life scores to help determine treatment: is restoring bowel continuity better than an ostomy? Colorectal Dis, 2002; 4: 41-7.

[67]. Renner, K; Rosen, HR; Novi G, et al. Quality of life after surgery for colorectal cancer: do we still need a permanent colostomy? Dis Colon Rectum, 1999; 42:1160-7.

[68]. Schmidt, CE; Bestmann, B; Kuchler, T; Longo, WE; Kremer, B. apud Ko et al e Kohler et al. In: Prospective evaluation of quality of life of patients receiving either abdominoperineal resection or sphincter-preserving procedure for rectal cancer. Annals of Surgical Oncology, 2005, 12(2): 117-23. 
[69]. Grumann, MM; Noack, EM; Hoffman, IA; Schlag, PM. Comparison of quality of life in patients undergoing abdominoperineal extirpation or anterior resection for rectal cancer. Ann Surg, 2001; 233: 149-56.

[70]. Shilder apud Penna, L. Imagem corporal: uma revisão seletiva da literatura. Psicologia- USP, 1990, São Paulo, 1(2): 167-74.

[71]. Martinsson, E; Josefsson, MEKA. Working capacity and quality of life after undergoing an ileostomy. Journal of Advanced Nursing, 1991, 16(9): 1035-41.

[72]. Trentini et al. Vivendo com um ostoma: um estudo preliminary. Revista Gaúcha de Enfermagem, 1992, Porto Alegre, 13(2): 22-8.

[73]. Santos, VLG. Reabilitaçao do ostomizado: em busca do ser saudável. Texto e Contexto Enf., 1992, Florianópolis, 1(2): 180-90. 


\subsection{Anexo I: Termo de Consentimento Livre e Esclarecido}

Meu nome é Simone Yuriko Kameo e estou desenvolvendo a pesquisa "Qualidade de vida do paciente com estoma intestinal secundário ao câncer cólon-retal", com o objetivo de investigar a qualidade de vida do paciente com estoma intestinal secundário ao câncer cólon-retal. Será feito a identificação das características sociais e clínicas da clientela portadora de estoma intestinal secundário ao câncer cólon-retal, além da identificação dos aspectos afetados na qualidade de vida dos pacientes colostomizados. Este estudo é necessário para se conhecer a qualidade de vida destes pacientes, já que estes passam por mudanças tanto físicas, psicológicas e sociais, e assim poder melhorar a qualidade destas vidas. Isto não traz risco e desconforto algum, e esperamos que traga benefícios, no sentido de poder melhorar ou minimizar os aspectos desgastantes nas vidas desta clientela. Se você tiver alguma dúvida em relação ao estudo ou não quiser mais fazer parte do mesmo, pode entrar em contato pelo telefone (79) 3217-5713. Se você estiver de acordo em participar, posso garantir que as informações fornecidas serão confidenciais e só serão utilizados neste trabalho.

Assinaturas:

Pesquisador principal

Pesquisador responsável

Eu, fui esclarecido sobre a pesquisa "Qualidade de vida do paciente com estoma intestinal secundário ao câncer colo-retal" e concordo que meus dados sejam utilizados na realização da mesma.

de de 20 RG: 
8.2 Anexo II: Coleta de dados sócio-clínico-demográficos dos estomizados

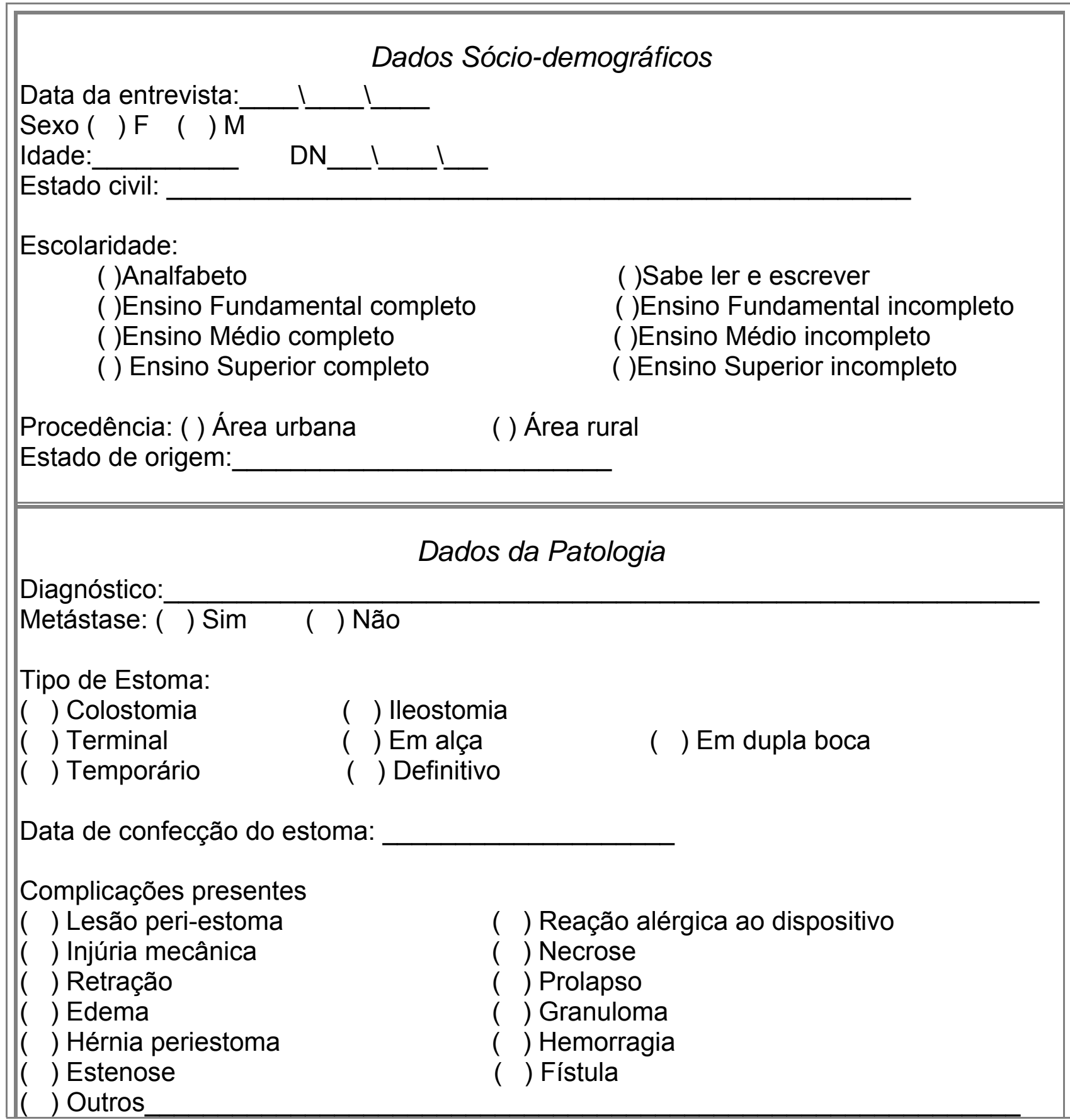




\subsection{Anexo III: Instrumento para coleta de dados sobre Qualidade de Vida - EORTC QLQ - C30 (Versão 3.0)}

Iniciais do nome:

Data da coleta |

Responda, por favor, a todas as perguntas fazendo um círculo no número que melhor se aplica a você. Não há respostas certas ou erradas. A informação que você fornecer permanecerá estritamente confidencial.

1. Você tem qualquer dificuldade quando faz grandes

Não Pouco $\begin{aligned} & \text { Modera Muito } \\ & \text { dament }\end{aligned}$
esforços, por exemplo carregar uma bolsa de 1 compras pesada ou uma mala?

2. Você tem qualquer dificuldade, quando faz uma grande caminhada?

3. Você tem qualquer dificuldade quando faz uma curta caminhada fora de casa?

4. Você tem que ficar numa cama ou na cadeira durante o dia?

5. Você precisa de ajuda para se alimentar, se vestir, se lavar ou usar o banheiro?

2

e

3

4

$2-3-4$

23

4

23

4

23

4

DURANTE A ÚLTIMA SEMANA:

Não Pouco Modera Muito dament

6. Você se sentiu limitado/a para realizar seu trabalho 1 ou cumprir suas atividades diárias?

7. Você se sentiu limitado/a em suas atividades de

1 lazer?

8. Você teve falta de ar?

9. Você tem tido dor?

10. Você precisou repousar?

11. Você tem tido problemas para dormir?

12. Você tem se sentido fraco/a?

13. Você tem tido falta de apetite?

14. Você tem se sentido nauseado/a?

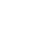


DURANTE A ÚLTIMA SEMANA:

15. Você tem vomitado?

16. Você tem ficado constipado?

17. Você tem tido diarréia?

18. Você esteve cansado/a?

19. A dor interferiu em suas atividades diárias?

20. Você tem tido dificuldade para se concentrar em

Não Pouco $\begin{array}{r}\text { Modera Muito } \\ \text { dament }\end{array}$ coisas, como ler jornal ou ver televisão?

21. Você se sente tenso/a?

22. Você esteve preocupado/a?

23. Você se sentiu irritado/a facilmente?

24. Você se sentiu deprimido/a?

25. Você tem tido dificuldade para se lembrar das coisas?

26. A sua condição física ou o tratamento médico tem interferido em sua vida familiar?

27. A sua condição física ou o tratamento médico tem interferido em suas atividades sociais?

28. A sua condição física ou o tratamento médico tem Ihe trazido dificuldades financeiras?

e

23

23

$1 \quad 2 \quad 3 \quad 4$

1

$2 \quad 3 \quad 4$

1

2

3

4

Para as seguintes perguntas, faça um círculo em volta do número entre 1 e 7 que melhor se aplica em você.

29. Como você classificaria a sua saúde em geral, durante a última semana?

$\begin{array}{lllllll}1 & 2 & 3 & 4 & 5 & 6 & 7 \\ \text { Péssima } & & & & & & \text { Ótima }\end{array}$

30. Como você classificaria a sua qualidade de vida global, durante a última semana?

$\begin{array}{lllllll}1 & 2 & 3 & 4 & 5 & 6 & 7 \\ \text { Péssima } & & & & & & \text { Ótima }\end{array}$


8.4 Anexo IV: Escala de qualidade de vida de Flanagan (1982)

\begin{tabular}{|c|c|c|c|c|c|c|}
\hline $\begin{array}{l}\text { DIMENSÕES/ } \\
\text { ESCALA }\end{array}$ & $\overline{R U I M}$ & REGULAR & INDIFERENTE & $\overline{\mathrm{BOM}}$ & $\begin{array}{l}\text { MUITO } \\
\text { BOM }\end{array}$ & OTIMO \\
\hline $\begin{array}{l}\text { 1) Bem estar físico e } \\
\text { material } \\
\text { Conforto material (casa, } \\
\begin{array}{l}\text { alimentação, } \\
\text { financeira). }\end{array}\end{array}$ & & & & & & \\
\hline $\begin{array}{l}\text { Saúde (estar fisicamente } \\
\text { bem e vigoroso). }\end{array}$ & & & & & & \\
\hline $\begin{array}{l}\text { 2) Relações com outras } \\
\text { pessoas } \\
\text { Relacionamento com pais, } \\
\text { irmãos e outros parentes - } \\
\text { comunicação, risita, } \\
\text { ajuda. }\end{array}$ & & & & & & \\
\hline Ter e criar filhos. & & & & & & \\
\hline $\begin{array}{l}\text { Relacionamento íntimo } \\
\text { com companheiro (a). }\end{array}$ & & & & & & \\
\hline $\begin{array}{l}\text { Amigos } \\
\text { próximos/compartilha } \\
\text { interesses e opiniões. }\end{array}$ & & & & & & \\
\hline
\end{tabular}

3) Atividades sociais, comunitárias e cívicas.

Ajuda e apoio a outras pessoas voluntariamente.

Participação

associações e atividades

de interesse público.

4) Desenvolvimento pessoal e realização:

Aprendizagem/freqüenta escola, aperfeiçoa conhecimentos.

Atividades domésticas

Atividades profissionais ou outras.

Comunicação criativa.

5) Recreação

Socialização/fazer amigos

Leitura, ouvir música, assistir TV, cinema e/ou esportes, e outros.

Participação em recreação ativa.

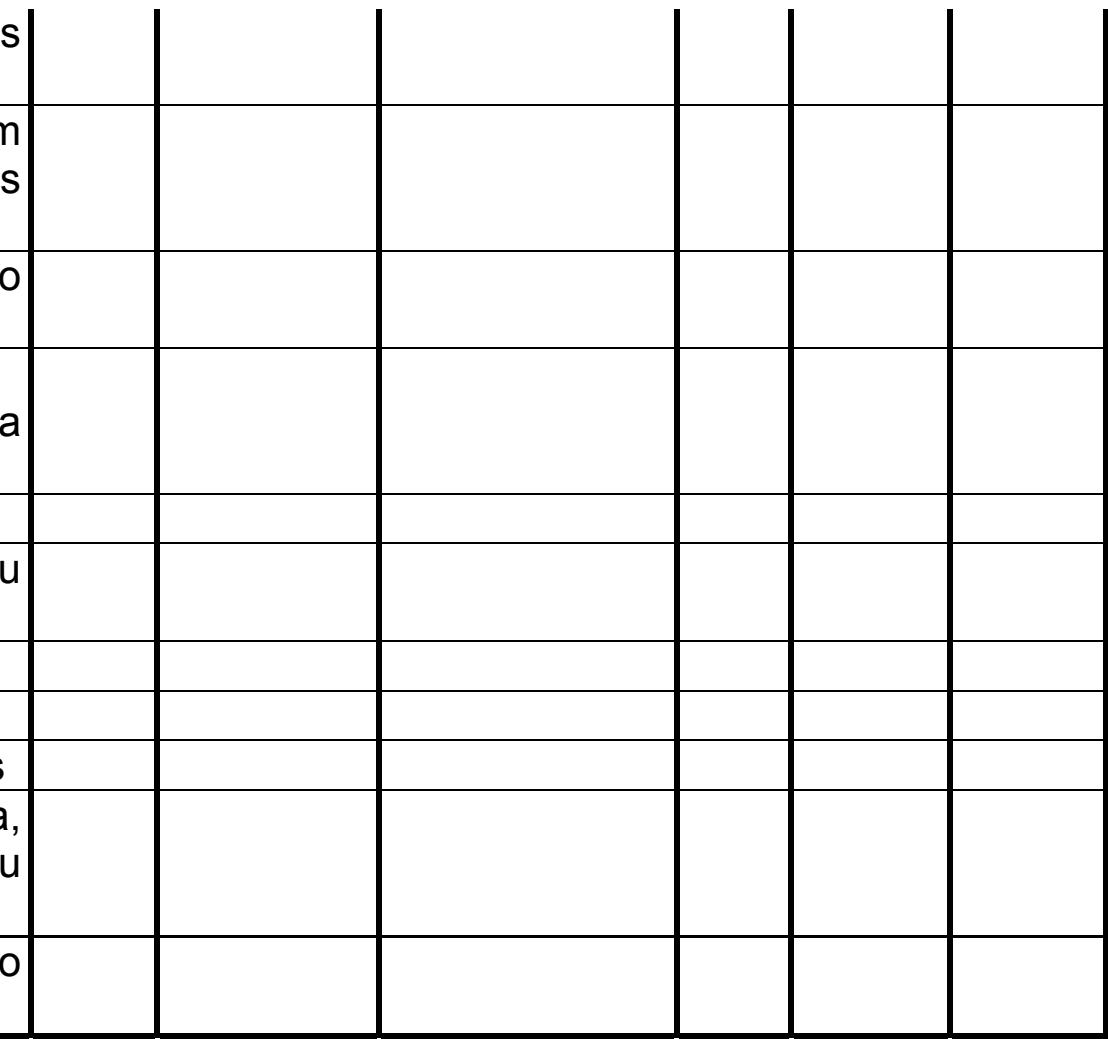




\section{FICHA CATALOGRÁFICA}

\section{Kameo, Simone Yuriko}

Qualidade de vida do paciente com ostomia intestinal secundária ao câncer colo-retal.Ribeirão Preto,2006.

119 p. : il. ; 30cm

Dissertação de Mestrado, apresentada à Escola de Enfermagem de Ribeirão Preto/USP - Área de concentração: Enfermagem Fundamental. Orientadora: Namie Okino Sawada.

1. Qualidade de vida. 2. Câncer colo-retal. 3.Ostomia intestinal. 